DIW BERLIN

Discussion Papers

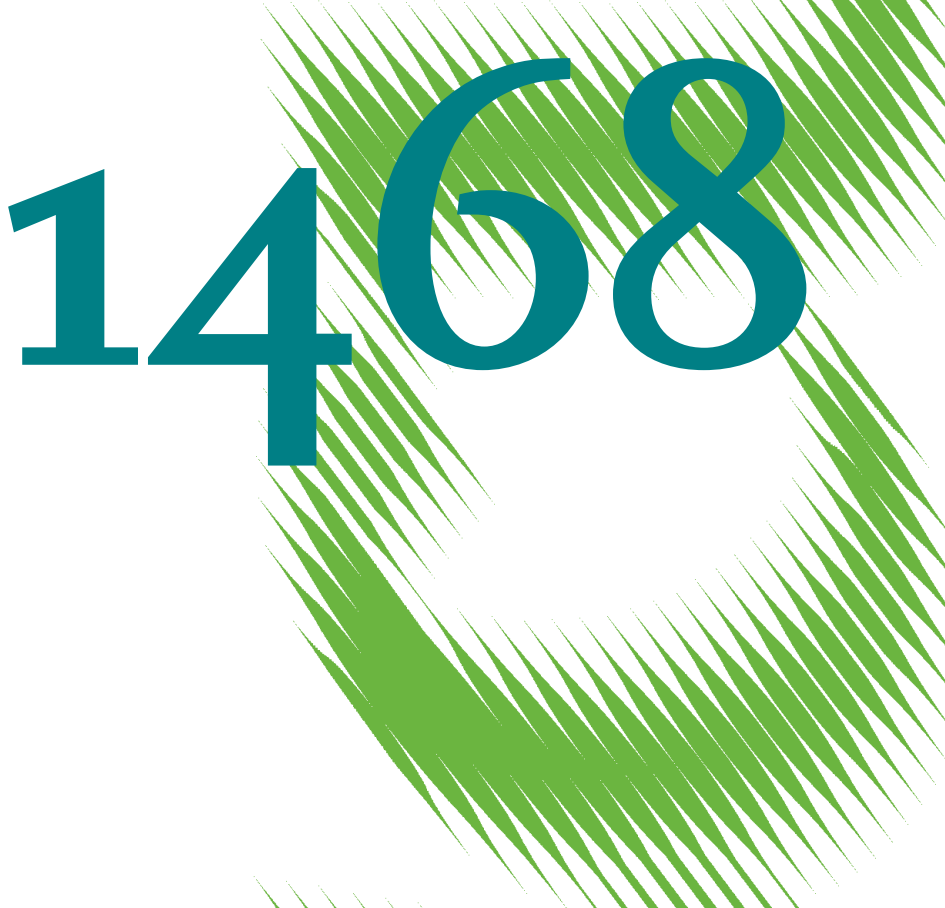

Optimal Social Assistance and Unemployment Insurance in a Life-Cycle Model of Family Labor Supply and Savings 
Opinions expressed in this paper are those of the author(s) and do not necessarily reflect views of the institute.

IMPRESSUM

(C) DIW Berlin, 2015

DIW Berlin

German Institute for Economic Research

Mohrenstr. 58

10117 Berlin

Tel. +49 (30) $89789-0$

Fax +49 (30) $89789-200$

http://www.diw.de

ISSN electronic edition 1619-4535

Papers can be downloaded free of charge from the DIW Berlin website:

http://www.diw.de/discussionpapers

Discussion Papers of DIW Berlin are indexed in RePEc and SSRN:

http://ideas.repec.org/s/diw/diwwpp.html

http://www.ssrn.com/link/DIW-Berlin-German-Inst-Econ-Res.html 


\title{
Optimal Social Assistance and Unemployment Insurance in a Life-cycle Model of Family Labor Supply and Savings
}

\author{
Peter Haan* and Victoria Prowse ${ }^{\dagger}$
}

March 25, 2015

\begin{abstract}
We analyze empirically the optimal design of social insurance and assistance programs when families obtain insurance by making labor supply choices for both spouses. For this purpose, we specify a structural life-cycle model of the labor supply and savings decisions of singles and married couples. Partial insurance against wage and employment shocks is provided by social programs, savings and the labor supplies of all adult household members. The optimal policy mix focuses mainly on Social Assistance, which provides a permanent universal household income floor, with a minor role for temporary earnings-related Unemployment Insurance. Reflecting that married couples obtain intra-household insurance by making labor supply choices for both spouses, the optimal generosity of Social Assistance decreases in the proportion of married individuals in the population. The link between optimal program design and the family context is strongest in low-educated populations.
\end{abstract}

Key Words: Life-cycle labor supply; Family labor supply; Unemployment Insurance; Social Assistance; Design of benefit programs; Intra-household insurance; Household savings; Employment risk; Added worker effect.

JEL Classification: J18; J68; H21; I38.

*FU Berlin and DIW Berlin, phaan@diw.de

†Department of Economics, Cornell University, prowse@cornell.edu 


\section{Introduction}

An established literature explores empirically the insurance-incentive trade-off inherent in the design of social insurance and assistance programs (e.g., Gruber, 1997, Chetty, 2008, Lentz, 2009, Low et al., 2010). This literature focuses on single individuals and on households that make a single labor supply decision. In this paper, we extend this literature by analyzing the optimal design of social insurance and assistance programs when married couples make labor supply choices for both spouses - a so-called family labor supply decision (Blundell et al., 2012). This extension is motivated by research showing that married couples obtain insurance by adjusting one spouse's labor supply in response to employment and wage shocks impacting the other spouse. Lundberg (1985) finds an "added worker effect" whereby women increase their own labor supply when their husbands' earnings decline. ${ }^{1}$ Similarly, Blundell et al. (2012) show that permanent shocks to an individual's wage are largely insured by adjustments of the individual's own labor supply combined with adjustments of the spouse's labor supply. Meanwhile, Cullen and Gruber (2000) demonstrate that the labor supply of wives is decreasing in the generosity of their husbands' Unemployment Insurance benefits. However, these papers do not explore the interaction between the intra-household insurance opportunities provided by family labor supply and the optimal design of social insurance and assistance programs. Another novelty of our analysis is to consider simultaneously the optimal generosities of social insurance and assistance programs. We focus on two key programs: Social Assistance, which guarantees a permanent universal household income floor; and Unemployment Insurance, which provides temporary earnings-related benefits to individuals who recently left employment. Low et al. (2010) find that people assign a higher value to an increase in Food Stamps - a social assistance benefit - than to a revenue equivalent increase in Unemployment Insurance, and Saporta-Eksten (2014) shows that the optimal design of Unemployment Insurance depends on the generosity of Food Stamps. Building from here, our analysis provides insights on the optimal design of the composite social insurance and assistance system.

We embed a social insurance and assistance system in a dynamic structural model of life-cycle labor supply, retirement and savings decisions that includes singles as well as married couples that make labor supply choices for both spouses. While singles have only one potential stream of labor earnings, married couples may partially insure themselves

\footnotetext{
${ }^{1}$ Triebe (2015) has recently replicated this finding using a similar sample to ours from the German Socio-Economic Panel. Added worker effects reflect both non-separabilities between the spouses' leisure times (Goux et al., 2014) and a preference for income replacement. Importantly for our proposes, both leisure-drive and income-driven adjustments of labor supply in response to shocks to the spouse's earnings imply that the family labor supply decision of married couples is relevant to the optimal design of social insurance and assistance programs.
} 
by adjusting either one spouse's or both spouses' labor supply in response to wage and employment shocks. We use the estimated life-cycle model to explore optimal household behavior and the welfare effects of social insurance and assistance programs. In terms of behavior, we find that married couples respond to adverse employment shocks suffered by one spouse by increasing the other spouse's labor supply. Leisure complementarities moderate the cross-spouse response to job loss. In terms of policy implications, we find that the optimal policy mix focuses mainly on Social Assistance, with a minor role for Unemployment Insurance. Reflecting the intra-household insurance opportunities provided by family labor supply, we also find that the optimal generosity of Social Assistance decreases in the proportion of married couples in the population. The link between optimal program design and the family context is present in high-educated and low-educated populations, but is stronger in the latter.

Our life-cycle model describes the labor supply, retirement and savings decisions of singles and married couples. Importantly, the model captures the insurance and incentive effects of Social Assistance and Unemployment Insurance, and reflects heterogeneity in these effects according to whether the household comprises a single adult or a married couple. Other features of the model that have particular relevance for our analysis include: explicit modeling of the labor supplies of both members of a married couple, which recognizes that family labor supply may provide intra-household insurance that substitutes for insurance from social insurance and assistance programs; between-spouse leisure complementarities, which may moderate the response of a spouse's labor supply to his or her partner's job loss; liquidity constraints that limit the ability of households to self-insure; heterogeneity in education, which generates a redistributive motive for social programs; and search decisions and endogenous quits, both of which may be subject to moral hazard effects from Social Assistance and Unemployment Insurance. The model further includes wage risk and employment risk, which generate demand for insurance. Households are forward looking, and thus the model captures interactions between the contemporaneous incentives presented by social insurance and assistance programs and the intertemporal incentives to accumulate human capital (see, e.g., Keane and Wolpin, 1997, Imai and Keane, 2004, Blundell et al., 2011, and Keane, 2014) and to accumulate entitlement to social insurance programs (see, e.g., French, 2005, Attanasio et al., 2008, Heathcote et al., 2009, and Low et al., 2010). ${ }^{2}$

The parameters of the life-cycle model are estimated using indirect inference applied to a panel sample of singles and married couples taken from the German Socio-Economic Panel (SOEP). The estimated model has good in-sample fit. Indeed, the estimated model

\footnotetext{
${ }^{2}$ Blau and Gilleskie (2006) and van der Klaauw and Wolpin (2008) analyze, respectively, health insurance and pension reforms with two-earner households. While these papers model couples, they focus on older populations, they do not include employment risk, and they do not compare insurance and assistance programs or explore the importance of the family unit for policy design.
} 
is able to replicate the observed life-cycle profiles of labor supply and wealth. The model also fits the joint distribution of the labor supply outcomes of wives and husbands, along with the cross-spouse and intertemporal wage correlations. Following, e.g., Todd and Wolpin (2006) and Low and Pistaferri (2010), we show that the estimated model is able to match existing reduced-form results. Specifically, we replicate results on the labor supply effects of changes in the level and duration of Unemployment Insurance benefits (e.g., Lalive et al., 2006, and Schmieder et al., 2012). For example, the estimated model implies that a one-week increase of the initial entitlement period increases the duration in nonemployment by $0.1-0.2$ weeks, which is in line with the previous literature. We take the consistency of the model with previous findings as evidence that the model is well-suited to analyzing questions surrounding the design of Social Assistance and Unemployment Insurance.

Based on the estimated model, we obtain several important results. First, we find that revenue neutral cuts in the generosity of either Social Assistance or Unemployment Insurance, holding the other program at its baseline generosity, solicit increases in employment and household wealth, indicating substitution between each of these social programs and intra-household insurance from labor supply and savings. The behavioral distortions created by Social Assistance and Unemployment Insurance manifest themselves differently, reflecting differences in how the programs are targeted. In particular, conditional on the welfare impact of the policy change, savings behavior is more sensitive to an increase in Social Assistance than to a revenue equivalent increase in Unemployment Insurance. Also, the effect of a marginal revenue neutral increase in the generosity of Social Assistance on the employment rate decreases in the benefit generosity, and is negligible at low levels of benefit generosity. In contrast, marginal revenue neutral increases in the generosity of Unemployment Insurance generate appreciable decreases in the employment rate at both high and low levels of benefit generosity.

Second, we derive results on the effective design of individual social programs. Given the baseline Unemployment Insurance system, we find that the optimal Social Assistance income floor for a married couple with two pre-school aged children is 966 Euros per month, which corresponds to $59 \%$ of the baseline generosity. Meanwhile, given the permanent household income floor provided by Social Assistance, the insurance-incentive trade-off implies that the provision of additional social protection through Unemployment Insurance is suboptimal. This result arises despite the time-limited nature of Unemployment Insurance, which allows benefits to be focused on people who recently left employment. Optimal reforms of Social Assistance and Unemployment Insurance yield meaningful welfare gains of worth, respectively, $2.53 \%$ and $2.91 \%$ of average life-time consumption.

Third, we demonstrate that the nature of the family unit has important implications for the optimal design of social assistance programs. Relative to a population of single 
individuals, the presence of married couples reduces the optimal generosity of Social Assistance by $12 \%$ in high-educated populations and by $18 \%$ in low-educated populations. The increasing importance of marriage to optimal program design as education decreases is consistent with intra-household insurance from marriage being most valuable to loweducated individuals, due to their relatively high employment risk and low wages. We find that couples optimally increase one spouse's labor supply in response to the other spouse's job loss, which shows that family labor supply provides intra-household insurance. Both husbands and wives increase labor supply in response to their spouses' job losses, although the response of wives is larger and more persistent. We find that withinhousehold complementarities between the leisure times of the husband and wife reduce the cross-spouse labor supply response to job loss. The latter result reflects that betweenspouse leisure complementarities partly offset the impact of job loss by providing married individuals with a utility benefit from joint non-work, and suggests that between-spouse leisure complementarities are an important input to optimal policy design.

Finally, we explore the optimal combination of social insurance and assistance programs. We find that the optimal policy mix focuses on permanent universal Social Assistance, with little or no role for temporary earnings-related Unemployment Insurance. In this assistance-orientated system, individuals who recently left employment and longterm non-workers receive similar levels of social support. This result expands the findings of Low et al. (2010), and shows that the lower baseline valuation of Unemployment Insurance, compared to the baseline valuation of social assistance programs, translates into a minimal optimal generosity for Unemployment Insurance. The desirability of an assistance-orientated system applies irrespective of the distributions of marriage and education in the population, and therefore this finding is not driven by education-based redistributive concerns or by factors that are specific to married couples. The population share of married individuals, however, impacts strongly on the optimal generosity of Social Assistance within the optimal policy mix; moving from a society of single individuals to one in which marriage and divorce occur at the empirical rates reduces the welfare-maximizing generosity of Social Assistance by 16-22\%, depending on education.

This paper builds on previous work that has linked optimal program design with empirical estimates of the effects of social insurance and assistance programs on consumption smoothing, search behavior and savings decisions. Gruber (1997), for example, explores how the optimal Unemployment Insurance replacement rate depends on the estimated effect of Unemployment Insurance on consumption smoothing and search. Chetty (2008) emphasizes the role of liquidity constraints in driving the optimal provision of Unemployment Insurance, and Lentz (2009) shows that the optimal Unemployment Insurance replacement rate decreases with household wealth; this important role for intra-household insurance from savings suggests that intra-household insurance from family labor supply may also be policy relevant. Our results also add to research that emphasises program 
interdependencies (see Keane and Moffitt, 1998, and Chan, 2013), and to a growing literature that makes comparisons between insurance-based and assistance-based social programs (see Low et al., 2010, Low and Pistaferri, 2010, and Saporta-Eksten, 2014). ${ }^{3}$

This paper proceeds as follows. Section 2 describes our model of households' labor supply, retirement and savings decisions over the life cycle. Section 3 describes the SOEP survey and our estimation sample. Section 4 outlines the indirect inference estimation procedure. Section 5 presents the structural parameter estimates, and explores the model's in-sample and out-of-sample goodness of fit. Section 6 discusses the trade-offs involved in designing social insurance and assistance systems, and reports our results on the behavioral and welfare effects of Social Assistance and Unemployment Insurance. This section closes by demonstrating the importance of the family unit to the optimal design of social programs. Section 7 concludes.

\section{Life-cycle Model}

\subsection{Overview}

We propose a discrete-time dynamic model of the labor supply, retirement and savings decisions of singles and married couples over the life cycle. Decisions are made semiannually, i.e., one period lasts for 6 months. Figure 1 illustrates the timing of events. Individuals enter the labor force from education. For those in the labor force, each period proceeds as follows: (i) marital status is updated; (ii) the household observes the woman's fertility outcome (if applicable) and each member's market wage, job destruction status and current-period preference shocks; (iii) the household chooses a search intensity for each household member who was non-employed or in education in the previous period; and (iv) job offers are realized, and the household makes labor supply, retirement and savings decisions. ${ }^{4}$

\footnotetext{
${ }^{3}$ Several papers provide theoretical insights into the optimal design of Unemployment Insurance, e.g., Shavell and Weiss (1979), Hopenhayn and Nicolini (1997), Shimer and Werning (2008) and Pavoni (2009) derive the optimal time path of Unemployment Insurance benefits, Pavoni et al. (2013) consider the optimal time path of insurance and assistance benefits when mandatory work and assisted search are policy instruments, Acemoglu and Shimer (1999) show that the optimal generosity of Unemployment Insurance depends on workers' willingness to accept employment risk, and Shimer and Werning (2007) propose an approach that is complementary to Baily (1978) and Chetty (2006) and relies on the reservation wage. Paserman (2008) and Spinnewijn (2015) study the optimal design of Unemployment Insurance with, respectively, hyperbolic discounting and biased beliefs.

${ }^{4}$ We do not distinguish between cohabitation and marriage, and individuals cannot marry and divorce in the same period. The timing of the transition from education into the labor force is assumed to be exogenous.
} 


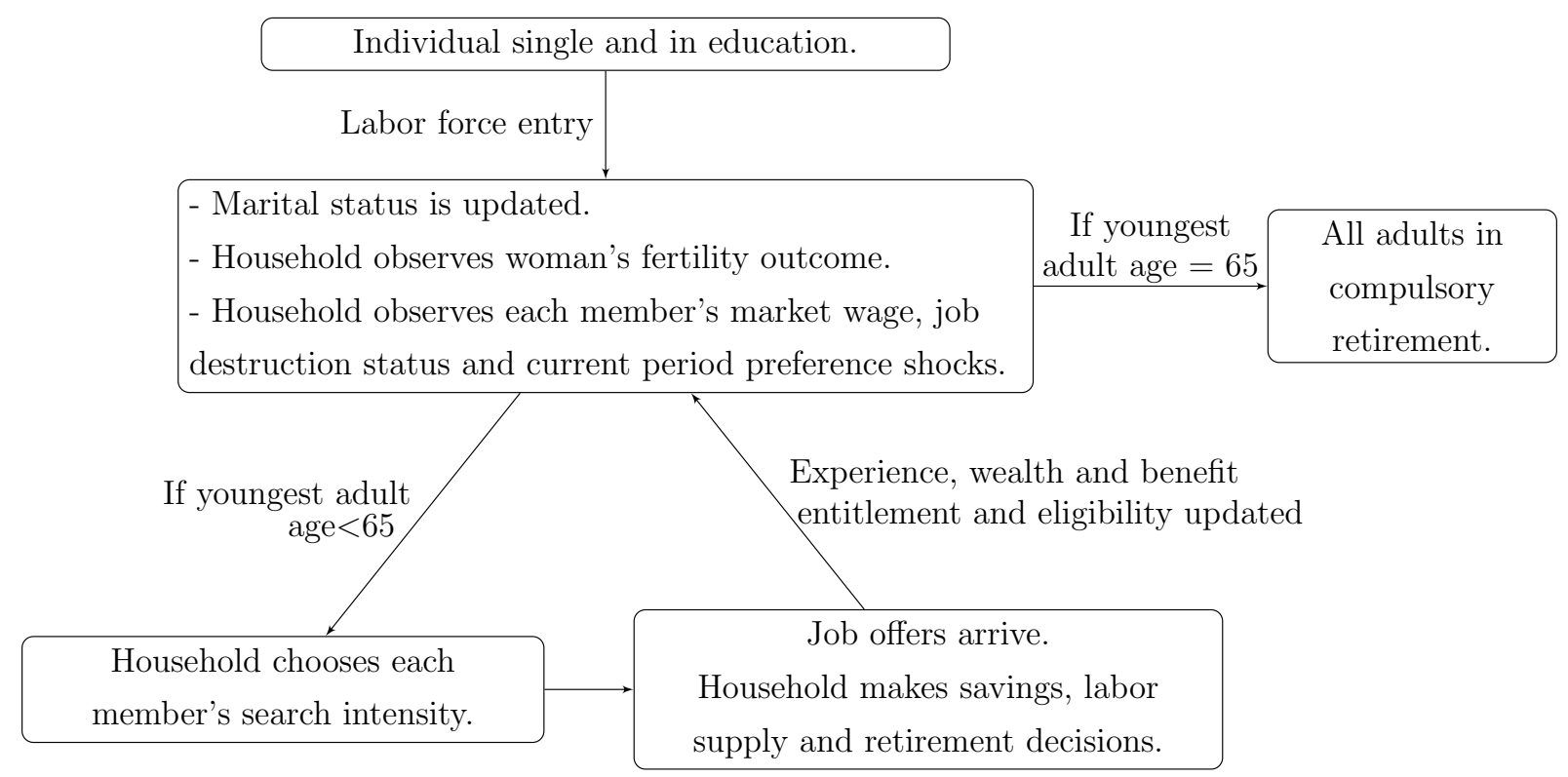

Figure 1: Timing of events over the life cycle.

The labor supply states at the individual level are: non-employment $(N E)$; full-time employment (FT, 40 hours of work per week); and, for women only, part-time employment ( $P T, 20$ hours of work per week). An individual permanently exits the labor force when he or she enters retirement $(R T)$, which is mandatory at age 65 years. Once the youngest household member reaches the compulsory retirement age there are no further opportunities for search or labor supply decisions. From this point onward, the household supplements any pension and social assistance benefits with the annuity value of the household's wealth when the youngest household member was age 65 . The model thus includes a life-cycle saving motive, as well as a precautionary motive for saving to smooth the marginal utility of consumption in the face of, e.g., wage shocks and job destructions.

Social insurance and assistance programs provide partial insurance against wage and employment shocks, and enter the model through the intertemporal budget constraint. Our policy analysis focuses on Social Assistance and Unemployment Insurance, although the model also includes a public pension system and child benefits. The model captures the moral hazard effects of Social Assistance and Unemployment Insurance on search behavior and on voluntary transitions out of employment, and further includes variation in the insurance, incentive and redistributive effects of Social Assistance and Unemployment Insurance by marital status. Labor supply and savings provide further sources of insurance. Married couples make labor supply choices for both spouses, and they thus obtain intra-household insurance from family labor supply, while singles have only one source of potential labor earnings.

We describe below: the specification of preferences (Section 2.3); the wage process (Section 2.4); labor market frictions (Section 2.5); the intertemporal budget constraint 
(Section 2.6); and optimal life-cycle behavior (Section 2.7). Appendix A describes the exogenous processes that determine marital status, spousal education, fertility outcomes and job destructions.

\section{$2.2 \quad$ Notational Definitions}

Women are indexed by $i$, and men are indexed by $j$. Age is indexed by $t$. One unit of $t$ represents 6 months of calender time, i.e., one model period. In married couples, the husband is $\Delta \equiv 5$ periods, i.e., 2.5 years, older than the wife. ${ }^{5} \widetilde{T}$ denotes the compulsory retirement age, which is 130 model periods, i.e., 65 years, for women and men. Women live until age $\bar{T}^{F}$ and men live until age $\bar{T}^{M}{ }^{6}$

Household level quantities, such as wealth and consumption, are indexed by $(i, j, t)$, with $i=\emptyset$ for a male-headed single household and $j=\emptyset$ for a female-headed single household. In married couples, $t$ indexes the age of the wife. The set of potentially feasible labor supply and retirement states is denoted by $\mathcal{D}^{F}=\{F T, P T, N E, R T\}$ for women and $\mathcal{D}^{M}=\{F T, N E, R T\}$ for men. ${ }^{7}$

\subsection{Preferences}

The per-period utility function of woman $i$ at age $t$ is given by:

$$
U^{F}\left(m_{i, j, t}, d_{i, t}, d_{j, t+\Delta}, s_{i, t}, \varepsilon_{i, t}\right)=u^{F}\left(m_{i, j, t}, d_{i, t}, d_{j, t+\Delta}\right)-\frac{s_{i, t}^{2}}{2}+\varepsilon_{i, t}\left(d_{i, t}\right),
$$

where $m_{i, j, t}$ denotes household consumption and $d_{i, t} \in \mathcal{D}^{F}$ denotes the woman's age $t$ labor supply and retirement outcome. If the woman is married then $d_{j, t+\Delta} \in \mathcal{D}^{M}$ denotes the husband's labor supply and retirement outcome when the woman is aged $t$. If the woman is single then $j=\emptyset$ and $d_{\emptyset, t+\Delta}$ denotes the absence of a husband. $s_{i, t}$ denotes the woman's age $t$ search intensity. As explained in Section 2.5, an individual who was employed in the previous period will not search, while search intensity is weakly positive for an individual who was non-employed in the previous period. The woman experiences time-varying labor supply and retirement state-specific preference shocks, $\varepsilon_{i, t}\left(d_{i, t}\right)$, that

\footnotetext{
${ }^{5}$ This assumption reflects the average male-female age difference for newly-formed married couples in the SOEP estimation sample.

${ }^{6}$ Based on the German Human Mortality Database, we estimate life expectancies at age 20 years equal to 79.74 years for women and 72.98 years for men.

${ }^{7}$ As discussed in Section 2.5, the set of choices that is actually, rather than potentially, feasible depends on: the individual's age, which determines retirement eligibility (see Appendix B); the individual's retirement status (retirement is an absorbing state); and job availability, which in turn depends on the individual's employment status in the previous period, the individual's current-period job destruction outcome and the success of any search activities.
} 
are observed by the household at the start of each period. Preference shocks are assumed to be independent over time, and contemporaneous preference shocks are assumed to be mutually independent and normally distributed with mean zero and standard deviation $\varsigma_{F S}$ for single women and $\varsigma_{F C}$ for married women.

The sub-utility function, $u^{F}$, displays non-separability between consumption and the woman's own leisure and, for married women, allows non-separability between the spouses' leisure times:

$$
u^{F}\left(m_{i, j, t}, d_{i, t}, d_{j, t+\Delta}\right)={\frac{\left(\eta^{F}\left(d_{i, t}, d_{j, t+\Delta}\right) m_{i, j, t} / E_{i, j, t}\right)}{1-\rho^{F}}}^{1-\rho^{F}},
$$

where $\rho^{F}$ is the woman's coefficient of relative risk aversion, and $E_{i, j, t}$ is a household equivalence scale. ${ }^{8}$ The woman's taste for consumption, $\eta^{F}\left(d_{i, t}, d_{j, t+\Delta}\right)$, depends on the household labor supply and retirement outcome and on demographic variables as follows:

$$
\begin{aligned}
\log \eta^{F}\left(d_{i, t}, d_{j, t+\Delta}\right)= & \sum_{k \in \mathcal{D}^{F}} \eta_{1, k}^{F} \mathbf{1}\left(d_{i, t}=k\right)+\sum_{k \in \mathcal{D}^{F}} \eta_{2, k}^{F} \mathbf{1}\left(d_{i, t}=k\right) X_{i, t}^{F}+ \\
& \eta_{3} \mathbf{1}\left(d_{i, t}=N E \cup d_{i, t}=R T\right) \times \ell\left(d_{j, t+\Delta}\right) .
\end{aligned}
$$

In the above, $X_{i, t}^{F}$ contains an indicator of the woman being aged 50 or older and indicators of the age category of the household's youngest child (with reference category being a child aged 6 or above or no children), and $\eta_{2, k}^{F} k \in \mathcal{D}^{F}$ measure the impacts of these demographic variables on the woman's state-specific taste for consumption. The parameters $\eta_{1, k}^{F}$ for $k \in \mathcal{D}^{F}$ reflect the preference for consumption in state $k$ of a single woman aged under 50 without young children. The final term in (3) allows the woman's preference for non-work to vary with her spouse's leisure time, $\ell\left(d_{j, t+\Delta}\right) .{ }^{9}$ We interpret the parameter $\eta_{3}$ as the strength of within-household between-spouse leisure complementarities.

The utility function and sub-utility function take the same form for men as for women. Child-related variables are omitted from men's preferences. ${ }^{10}$ As described in Section 2.7.2, a married couple's objective function is based on a constant-weighted average of spouses' utilities. In the empirical analysis, we estimate the weight, $\alpha \in[0,1]$, attached to the woman's utility in the married couple's objective function.

\subsection{Wage Process}

We posit an individual-level process for woman $i$ 's age $t$ market wage, $W_{i, t}$. Following, e.g., Low et al. (2010), sample wage observations, $\widetilde{W}_{i, t}$ are mismeasured variants of the

\footnotetext{
${ }^{8}$ We use the equivalence scale implicit in the German Social Assistance system. See Appendix C.

${ }^{9}$ The spouse's leisure time is normalized to 1 for a non-working spouse, 0.5 for a part-time working spouse, and 0 a for full-time working spouse. Spousal leisure time is zero for a single individual.

${ }^{10}$ Non-employment and retirement are assumed to be identical in terms of their complementarity with consumption, and retirement and non-employment combined form the reference category. Formally, for women we impose $\eta_{1, N E}^{F}=\eta_{1, R T}^{F}=0$ and $\eta_{2, N E}^{F}=\eta_{2, R T}^{F}=0$, and likewise for men.
} 
corresponding market wages. By modeling the wage process jointly with labor supply and retirement behavior, we account explicitly for the effect of wage-based selection into employment on the distribution of accepted wages.

The sampled accepted $\log$ real market wage of women $i$ at age $t$ is given by:

$$
\log \widetilde{W_{i, t}}=\beta_{1}^{F}+\beta_{2}^{F} \mathbf{1}\left(\text { Education }_{i} \geq 12 \text { years }\right)+\beta_{3}^{F} \operatorname{Exp}_{i, t}+\beta_{4}^{F} \kappa_{i, t}+\nu_{i, t}
$$

In the above, Exp denotes years of experience; this variable is zero at the time of the individual's entry into the labor force from full-time education, and increases by 0.5 for each period of full-time work and 0.25 for each period of part-time work. ${ }^{11}$ The unobserved component of the woman's market wage, $\kappa_{i, t}$, may be transitory, persistent or permanent, depending on the parameter values. We assume that $\kappa_{i, t}$ is discrete with $\kappa_{i, t} \in\{0,1\}$. Subsequent to the woman's transition into the labor force from education, $\kappa_{i, t}$ evolves according to:

$$
\kappa_{i, t}=\mathbf{1}\left(\theta_{0}^{F}\left(1-\kappa_{i, t-1}\right)+\theta_{1}^{F} \kappa_{i, t-1}+\epsilon_{i, t} \geq 0\right),
$$

where the $\epsilon \mathrm{S}$ are assumed to be serially independent at the individual level with $\epsilon_{i, t} \sim$ $N(0,1)$. A woman's wage unobservable at the time of entry into the labor force from education is a draw from the steady state distribution. ${ }^{12}$ The final term $\nu_{i, t} \sim N\left(0, \sigma_{\nu F}^{2}\right)$ represents measurement error that affects the sample wage but that is absent from the market wage. Measurement errors are assumed to occur independently over time.

The wage process for men is obtained by replacing $F$ by $M$ and $i$ by $j$ in (4), (5) and (6). Thus, all parameters of the wage process may vary by gender. This aspect of the specification captures gender differences in labor market conditions and labor market-related behaviors. For example, a difference in the probability of a positive wage shock by gender may result from gender differences in risk taking, competitiveness or occupational choice, among other mechanisms. In the spirit of, e.g., Attanasio et al. (2008) and Blundell et al. (2012), contemporaneous market wage shocks may be correlated between spouses in the same household. Specifically, we assume $\operatorname{cov}\left(\epsilon_{i, t}, \epsilon_{j, t+\Delta}\right)=\varrho$, while non-contemporaneous wage shocks are assumed to be independent across spouses. ${ }^{13}$ Measurement errors are

\footnotetext{
${ }^{11}$ This experience variable also determines pension income. See Appendix B.

${ }^{12}$ Solving for the steady state, a proportion $\Theta^{F}$ of women have the high wage unobservable $(\kappa=1)$, where:

$$
\Theta^{F}=\frac{\Phi\left(\theta_{0}^{F}\right)}{1+\Phi\left(\theta_{0}^{F}\right)-\Phi\left(\theta_{1}^{F}\right)},
$$

and $\Phi()$ denotes the standard normal cumulative distribution function.

${ }^{13}$ In Section 5.1, we translate the estimated between-spouse correlation of $\epsilon$ into a between-spouse correlation of the wage unobservable, $\kappa$.
} 
assumed to occur independently over spouses. ${ }^{14}$

In Section 5.2, we show that the estimated life-cycle model is able to fit the sample values of the intertemporal wage correlation and the between-spouse wage correlation. The estimated model also replicates closely the observed pattern of dynamics within the wage distribution.

\subsection{Labor Market Frictions}

Each period an employed individual experiences a job destruction with a probability that varies by gender, age, education and marital status. An individual who experiences a job destruction cannot search or work in the current period. Job destructions thus constitute a substantial risk for employed individuals. ${ }^{15}$ Meanwhile, an employed individual who is not subject to a job destruction may remain in employment, if he or she chooses.

A non-employed individual may move into employment only if a job offer is received in the current period. The job offer probability is proportional to the individual's search intensity, and depends on individual characteristics through a factor of proportionality $\chi_{i, t}$. Formally, the job offer probability for woman $i$ who searches with intensity $s_{i, t} \in\left[0,1 / \chi_{i, t}\right]$ is given by:

$$
\operatorname{Pr}(\text { Job offer })=\chi_{i, t} s_{i, t}
$$

where

$$
\log \left(\chi_{i, t}\right)=\chi_{1}^{F}+\chi_{2}^{F} \mathbf{1}\left(\text { Age }_{i, t} \geq 50\right)+\chi_{3}^{F} \mathbf{1}\left(\text { Education }_{i} \geq 12 \text { years }\right)+\chi_{4}^{F} \operatorname{Married}_{i, t} \cdot(8)
$$

The job offer probability for men is obtained by replacing $F$ by $M$ and $i$ by $j$ in (7) and (8).

\subsection{Intertemporal Budget Constraint}

With no marriage or divorce at time $t$, the intertemporal budget constraint for household $(i, j)$ is given by:

$$
A_{i, j, t}=A_{i, j, t-1}(1+r)+y_{i, j, t}-m_{i, j, t}
$$

\footnotetext{
${ }^{14}$ The household is assumed to have no information, beyond that given above, about the values of future market wage shocks. Blundell et al. (2012) find little evidence of anticipation of wage shocks; for further discussion see Blundell and Preston (1998), Pistaferri (2001, 2003) and Guvenen (2007).

${ }^{15}$ We estimate the job destruction probabilities prior to estimation of the parameters of the life-cycle model (see Appendix A.4). Analysis of our sample reveals variation in the job destruction rate by marital status, as well as by education, gender and age.
} 
where $A_{i, j, t}$ denotes the combined net value of the household's financial, housing and durable assets, $r$ is the real interest rate, assumed to be $3 \%$, and $y_{i, j, t}$ is the net-oftax value of the household's income from employment and social programs. Marriage augments household assets by the assets of the incoming spouse. In the event of divorce, household assets are assumed to be divided equally between the spouses.

Households are assumed to be unable to borrow against future earnings or future entitlements to benefits from social programs. Reflecting this, household assets must be non-negative:

$$
A_{i, j, t} \geq 0
$$

This borrowing constraint amplifies the insurance motive for Social Assistance and Unemployment Insurance to smooth the marginal utility of consumption over the life cycle in the presence of shocks, such as wage shocks and job destructions. Given heterogeneity in education, Social Assistance and Unemployment Insurance may also be socially desirable on redistributive grounds. See Section 6.1 for further discussion.

\subsubsection{Household Net Income}

Based on the German tax and benefit system, the net-of-tax value of household income for couple $(i, j)$ in period $t$ is given by:

$$
\begin{aligned}
y_{i, j, t}= & W_{i, t} h_{i, t}+\mathrm{UI}_{i, t}+\text { Pension }_{i, t}-\mathrm{SSC}_{i, t}+ \\
& W_{j, t+\Delta} h_{j, t+\Delta}+\mathrm{UI}_{j, t+\Delta}+\text { Pension }_{j, t+\Delta}-\mathrm{SSC}_{j, t+\Delta}+ \\
& \mathrm{SA}_{i, j, t}-\operatorname{Tax}_{i, j, t}+\mathrm{CB}_{i, j, t}-\mathrm{CC}_{i, j, t} .
\end{aligned}
$$

In the above, UI denotes Unemployment Insurance benefits, SSC denotes Social Security Contributions, and Pension denotes public pension benefits; all three schemes are administered at the individual level. SA and Tax denote Social Assistance benefits and income tax respectively; both programs are administered at the household level. CB denotes child benefits, paid through the benefit system, and CC denotes child-care costs associated with employment. $h$ denotes hours of work. The net income for a single household is obtained by taking (11) and suppressing the earnings, Unemployment Insurance, Pension, and Social Security Contributions of the person with the opposite gender to that of the household head. Children are assumed to reside in the mother's household. Child benefits and child-care costs therefore do not affect a single man's net income.

Our analysis of interactions between social insurance and assistance and intra-household insurance centers on household-level Social Assistance benefits and individual-level Unemployment Insurance benefits. Our models of these programs are described below in Sections 2.6.2 and 2.6.3. The treatment of the remaining components of the budget constraint is described in Appendix B. 


\subsubsection{Unemployment Insurance}

Unemployment Insurance benefits provide eligible and entitled non-employed individuals with benefits that replace a fraction of previous net earnings. We use the following formula for weekly Unemployment Insurance benefits:

$$
\mathrm{UI}_{t}=\operatorname{Elig}_{t} \times \mathbf{1}\left(\mathrm{UIEnt}_{t}>0\right) \times \mathrm{RR} \times \mathrm{NW}_{t} \times \mathrm{PH}_{t} .
$$

The replacement rate, $\mathrm{RR}$, is 0.6 for an individual without dependent children or 0.67 if the individual has one or more dependent children. The net hourly wage, $\mathrm{NW}_{t}$, is determined from the individual's market wage (see Section 2.4) and the tax schedule (see Appendix B). Hours of work in previous employment, $\mathrm{PH}_{t}$, are 40 if the individual entered non-employment from full-time work and 20 if the individual entered non-employment from part-time work. ${ }^{16}$

An individual's Unemployment Insurance entitlement period, UIEnt ${ }_{t}$, is initialized at the time of entry to non-employment. Reflecting the German system, the initial entitlement period is an increasing function of age: an individual who is aged under 45 at the start of his or her non-employment spell has an initial entitlement period of 12 months, while individuals entering non-employment at age 45-46, 47-56 and greater than or equal to 57 have initial entitlement periods of 18,24 and 30 months respectively. ${ }^{17}$ The entitlement period evolves through the non-employment spell as follows:

$$
\text { UIEnt }_{t}=\max \left\{\text { UIEnt }_{t-1}-6,0\right\} .
$$

An individual's Unemployment Insurance eligibility, $\operatorname{Elig}_{t} \in\{0,1\}$, is determined at the time of entry to non-employment and is fixed over the non-employment spell. Specifically, an individual entering non-employment is eligible $\left(\right.$ Elig $\left._{t}=1\right)$ for Unemployment Insurance benefits if he or she was continuously employed in the past year or entered employment in the past year with remaining Unemployment Insurance entitlement, and otherwise the individual is ineligible $\left(\right.$ Elig $\left._{t}=0\right) .{ }^{18}$

\footnotetext{
${ }^{16}$ Additionally, Unemployment Insurance benefits are capped at 1,750 Euros per month.

${ }^{17}$ Given the semi-annual decision making frequency, the initial Unemployment Insurance entitlement period corresponds to $2,3,4$ or 5 model periods.

${ }^{18}$ According to the German legislation, individuals who quit their job and voluntarily make a transition into non-employment must wait three months before starting to receive Unemployment Insurance benefits. We neglect this rule because eligible individuals are seldom prevented from claiming Unemployment Insurance immediately upon entering non-employment. Specifically, our calculations based on administrative data collected by the German Federal Employment Agency for the year 2000 show that less than $5 \%$ of eligible new entrants to unemployment were sanctioned for quitting previous employment (see Bundesagentur für Arbeit, 2013).
} 
Formally, eligibility for Unemployment Insurance when non-employed evolves according to:

$$
\operatorname{Elig}_{t}=\left\{\begin{array}{r}
1 \text { if entered non-employment at } t, \text { and employed at } t-1 \text { and } t-2, \\
1 \text { if entered non-employment at } t, \text { and entered employment at } t-1 \text { with } \\
\text { non-zero UI entitlement }\left(\text { UIEnt }_{t-1}>0\right), \\
0 \text { if entered non-employment at } t, \text { and entered employment at } t-1 \text { with } \\
\text { zero UI entitlement (UIEnt } \left.{ }_{t-1}=0\right), \\
\text { Elig }_{t-1} \text { if non-employed at } t-1 .
\end{array}\right.
$$

Unemployment Insurance benefits are paid without regard to the spouse's earnings, and benefits are not linked to the household's interest income; therefore Unemployment Insurance benefits may be received by non-employed individuals residing in households with substantial earned or unearned income. Further, there is no wealth test; an eligible and entitled non-employed individual receives Unemployment Insurance benefits irrespective of his or her ability of smooth the marginal utility of consumption by drawing on household savings.

\subsubsection{Social Assistance}

Social Assistance is a household-level benefit that provides a permanent income floor to wealth-poor households. Broadly based on the German legislation, we use the following formula for household Social Assistance benefits:

$$
\begin{aligned}
& \mathrm{SA}_{i, j, t}= \mathbf{1}\left(A_{i, j, t}<10,000 \text { Euros }\right) \times \\
& \max \left\{\mathrm{SAFloor}-\mathrm{UI}_{i, t}-\mathrm{UI}_{j, t+\Delta}-W_{i, t} h_{i, t}-W_{j, t+\Delta} h_{j, t+\Delta}-\right. \\
&\left.\quad \text { Pension }_{i, t}-\text { Pension }_{j, t+\Delta}-\mathrm{CB}_{i, j, t}, 0\right\} .
\end{aligned}
$$

In the above, SAFloor is the Social Assistance income floor, and is defined to include housing benefits. The Social Assistance income floor is 600 Euros per month for a single household without children, and increases with the number of adults and children in the household - e.g., the Social Assistance income floor for a married couple with two pre-school aged children is 1,638 Euros per month. Appendix C provides a complete description of the Social Assistance income floor.

According to (14), Social Assistance benefits are withdrawn at a rate of $100 \%$ against the earnings, Unemployment Insurance benefits and pension income of all household members, and are withdrawn at a rate of $100 \%$ against child benefits. ${ }^{19}$ Social Assistance

\footnotetext{
${ }^{19}$ We ignore the lower withdrawal rate against earnings that applies to households with very low earnings. This is without consequence because modeled employment is at least 20 hours of work per week, thus ensuring that earnings are too high to qualify for the lower withdrawal rate.
} 
benefits are therefore focused on those households with little or no income from other sources. Further, Social Assistance benefits are only paid to households with assets that are worth less than 10,000 Euros.

\subsection{Optimal Life-cycle Behavior}

We characterize optimal life-cycle behavior using the value functions for single and married women and men. Given the forward looking nature of the dynamic problem, the optimization problems facing singles and married couples are interdependent: a single individual's decisions are partly driven by the expected consequences if he or she marries in the future, and a married couple's decisions are influenced by the expected consequences for each spouse in the event of divorce.

\subsubsection{Singles}

First, consider a single woman. The woman's choice problem ends when she reaches the compulsory retirement age, $\widetilde{T}$. From the compulsory retirement age onward the woman cannot search or work, and consumes pension and Social Assistance benefits plus the actuarially fair annuity value of household wealth at the compulsory retirement age. ${ }^{20}$ The woman's terminal value function is given by:

$$
\bar{V}^{F s}\left(\Psi_{i, \widetilde{T}}\right)=\mathbb{E}\left[\sum_{\tau=\widetilde{T}}^{\bar{T}^{F}} \delta^{(\tau-\widetilde{T})} u^{F}\left(m_{i, \emptyset, \widetilde{T}}, d_{i, \widetilde{T}}, d_{\emptyset, \widetilde{T}+\Delta}\right) \mid \Psi_{i, \widetilde{T}}\right],
$$

where $d_{i, \widetilde{T}}$ takes the value $R T$, indicating that the woman is retired, $d_{\emptyset, \widetilde{T}+\Delta}$ denotes the absence of a husband, and $\Psi_{i, t}$ denotes the woman's state variables at age $t .^{21}$

In each period prior to the compulsory retirement age, a single woman's optimization problem proceeds in two stages. First, search intensity is optimized. A job offer may arrive, and the set of feasible labor supply and retirement choices is observed by the household. Second, the household optimizes consumption, labor supply and retirement behavior. This within-period problem is solved backwards: we determine optimal consumption, labor supply and retirement behavior for each possible set of feasible labor

\footnotetext{
${ }^{20}$ Annuity values are computed assuming a real interest rate of $3 \%$. The annuity calculation for a single household is based on the individual's gender-specific life expectancy at the compulsory retirement age, while the annuity calculation for a married couple is based on the wife's life expectancy at the compulsory retirement age.

${ }^{21}$ The woman's state space, $\Psi_{i, t}$, contains the following characteristics of the woman: age; education category; persistent wage type; Unemployment Insurance eligibility; Unemployment Insurance entitlement period; previous hours; job destruction status; employment and retirement status in the previous period; household wealth; current period preference shocks; and the age of the first-born child.
} 
supply and retirement choices, and then solve for the optimal search intensity, taking into account the effect of search on the probability of employment constraints.

Prior to the compulsory retirement age, the labor supply and retirement-specific value functions for woman $i$ are given by:

$$
\begin{aligned}
V_{t}^{F s}\left(d \mid s, \Psi_{i, t}\right)= & U^{F}\left(m^{*}(d), d, d_{\emptyset, t+\Delta}, s, \varepsilon_{i, t}\right)+ \\
& \delta \mathbb{E}\left[\phi_{t+1}^{F s} V_{t+1}^{F s}\left(\Psi_{i, t+1}\right)+\left(1-\phi_{t+1}^{F s}\right) V_{t+1}^{F c}\left(\Psi_{i, t+1}, \Phi_{j, t+\Delta+1}\right) \mid \Psi_{i, t}, d\right], \\
& \text { for } d \in \mathcal{D}^{F} .
\end{aligned}
$$

In the above, $\delta=\sqrt{0.98}$ is the semi-annual subjective time discount factor, $s$ denotes the woman's search intensity, and $\Phi_{j, t}$ denotes potential future husband $j$ 's age- $t$ state variables. $^{22}$ The single woman's value function reflects the likelihood of marriage in the next period: her value function in the next period is the sum of the probability of remaining single, $\phi_{t+1}^{F s}$, times the single woman's value function at age $t+1, V_{t+1}^{F s}\left(\Psi_{i, t+1}\right)$, and the probability of marriage in the next period times the married woman's value function at age $t+1, V_{t+1}^{F c}\left(\Psi_{i, t+1}, \Phi_{j, t+\Delta+1}\right) .{ }^{23}$ The value function for a married woman is defined in Section 2.7.2. Last, $m^{*}(d)$ is the consumption choice that maximizes the labor supply and retirement-specific value function, subject to the intertemporal budget constraint and the non-negativity constraint on household wealth.

We now characterize optimal labor supply and retirement behavior given the set of feasible choices, as determined by the outcome of search activities, job destructions and the age-based restrictions on retirement eligibility. Let $D_{k}^{F}$ for $k=1, \ldots, K^{F}$ denote all possible sets of feasible employment and retirement choices. Given the set of feasible choices $D_{k}^{F}$, the single woman chooses the labor supply and retirement alternative with the highest choice-specific value function:

$$
d_{i, t}^{*}\left(D_{k}^{F}\right)=\underset{d \in D_{k}^{F}}{\operatorname{argmax}} V_{t}^{F s}\left(d \mid s, \Psi_{i, t}\right) .
$$

The single woman's optimal search intensity, $s_{i, t}^{*}$, is given by:

$$
s_{i, t}^{*}=\underset{s \in\left[0,1 / \chi_{i, t}\right]}{\operatorname{argmax}}\left\{\sum_{k=1}^{K^{F}} P\left(D_{k}^{F} \mid s, \Psi_{i, t}\right) V_{t}^{F s}\left(d_{i, t}^{*}\left(D_{k}^{F}\right) \mid s, \Psi_{i, t}\right)\right\},
$$

${ }^{22}$ The man's state space, $\Phi_{j, t}$, contains all variables that appear in the woman's state space (see footnote 21), except for previous hours and the age of the first-born child.

${ }^{23}$ Assumptions on expectations about the observable characteristics of future spouses reflect the modal in-sample pattern of marriage matching: an individual expects that his or her future spouse will enter the marriage with the same education, employment status, and Unemployment Insurance entitlement and eligibility as him or herself; individuals expect that the husband will enter the marriage with $7 \%$ more experience and 5\% more wealth than the wife; and a man expects his future wife to enter the marriage without preexisting children. Regarding the wage unobservables, an individual expects any future spouse to enter the marriage with the same wage unobservable as him or herself. 
where $P\left(D_{k}^{F} \mid s, \Psi_{i, t}\right)$ is the probability of the set $D_{k}^{F}$ of feasible labor supply and retirement choices given search intensity $s$. Evaluating the term in braces in (18) at the optimal search intensity, $s_{i, t}^{*}$, obtains the single woman's value function, $V_{t}^{F s}\left(\Psi_{i, t}\right)$. A single man's value function is obtained in the same way.

\subsubsection{Married Couples}

A married couple's choice problem ends when the wife reaches the compulsory retirement, $\widetilde{T}$, and therefore when the husband is age $\widetilde{T}+\Delta$. Once the wife reaches the compulsory retirement age, neither spouse can search or work, and the household consumes pension and Social Assistance benefits plus the actuarially fair annuity value of household wealth at the time when the wife reached the compulsory retirement age. The terminal value for woman $i$ in married couple $(i, j)$ is given by:

$$
\bar{V}^{F c}\left(\Psi_{i, \widetilde{T}}, \Phi_{j, \widetilde{T}+\Delta}\right)=\mathbb{E}\left[\sum_{\tau=\widetilde{T}}^{\bar{T}^{F}} \delta^{(\tau-\widetilde{T})} u^{F}\left(m_{i, j, \widetilde{T}}, d_{i, \widetilde{T}}, d_{j, \widetilde{T}+\Delta}\right) \mid \Psi_{i, \widetilde{T}}, \Phi_{j, \widetilde{T}+\Delta}\right],
$$

and the terminal value for man $j$ in married couple $(i, j)$ is given by:

$$
\bar{V}^{M c}\left(\Psi_{i, \widetilde{T}}, \Phi_{j, \widetilde{T}+\Delta}\right)=\mathbb{E}\left[\sum_{\tau=\widetilde{T}+\Delta}^{\bar{T}^{M}} \delta^{(\tau-\widetilde{T}-\Delta)} u^{M}\left(m_{i, j, \widetilde{T}}, d_{i, \widetilde{T}}, d_{j, \widetilde{T}+\Delta}\right) \mid \Psi_{i, \widetilde{T}}, \Phi_{j, \widetilde{T}+\Delta}\right] .
$$

In the two above equations, $d_{i, \widetilde{T}}$ and $d_{j, \widetilde{T}+\Delta}$ take the value $R T$, indicating that both spouses are retired. The married couple's objective function is formed from an $\alpha$-weighted average of the spouses' utilities. Therefore, the terminal value function for the married couple takes the form:

$$
\bar{V}^{F M}\left(\Psi_{i, \widetilde{T}}, \Phi_{j, \widetilde{T}+\Delta}\right)=\alpha \bar{V}^{F c}\left(\Psi_{i, \widetilde{T}}, \Phi_{j, \widetilde{T}+\Delta}\right)+(1-\alpha) \bar{V}^{M c}\left(\Psi_{i, \widetilde{T}}, \Phi_{j, \widetilde{T}+\Delta}\right) .
$$

In each period prior to the wife reaching the compulsory retirement age, the couple's optimization problem proceeds in two stages, as for singles. First, search intensities are optimized and job offers may arrive. Second, the household optimizes consumption, labor supply and retirement behavior. We have the following labor supply and retirementspecific value functions for the married couple prior to the wife reaching the compulsory retirement age:

$$
\begin{aligned}
V_{t}^{F M}\left(d^{F}, d^{M} \mid s^{F}, s^{M}, \Psi_{i, t}, \Phi_{j, t+\Delta}\right)= & \alpha U^{F}\left(m^{*}\left(d^{F}, d^{M}\right), d^{F}, d^{M}, s^{F}, \varepsilon_{i, t}\right)+ \\
& (1-\alpha) U^{M}\left(m^{*}\left(d^{F}, d^{M}\right), d^{F}, d^{M}, s^{M}, \varepsilon_{j, t+\Delta}\right)+ \\
& \delta \mathbb{E}\left[\left(1-\phi_{t+1}^{c}\right)\left(\alpha V_{t+1}^{F s}\left(\Psi_{i, t+1}\right)+(1-\alpha) V_{t+\Delta+1}^{M s}\left(\Phi_{j, t+\Delta+1}\right)\right)+\right. \\
& \left.\phi_{t+1}^{c} V_{t+1}^{F M}\left(\Psi_{i, t+1}, \Phi_{j, t+\Delta+1}\right) \mid \Psi_{i, t}, \Phi_{j, t+\Delta}, d^{F}, d^{M}\right], \\
& \text { for } d^{F} \in \mathcal{D}^{F} \text { and } d^{M} \in \mathcal{D}^{M} .
\end{aligned}
$$


In the above, $\phi_{i, t+1}^{c}$ is the probability that the spouses remain married, and $m^{*}\left(d^{F}, d^{M}\right)$ denotes the consumption choice that maximizes the labor supply and retirement-specific value function, again subject to the intertemporal budget constraint and the non-negativity constraint on household wealth. The married couple's value function reflects the possibility of divorce: the married couple's value function in the next period is weighted by the probability that the marriage survives, and the complementary probability is attached to an $\alpha$-weighted average of value functions of single women and men (see Section 2.7.1). van der Klaauw and Wolpin (2008) and Fernández and Wong (2014) use similar preference specifications in studies of, respectively, the effect of Social Security on household retirement behavior and the effect of divorce risk on female labor force participation.

Let $D_{k}^{c}$ for $k=1, \ldots, K^{c}$ denote all possible sets of feasible employment and retirement choices for a married couple. Given the set of feasible labor supply and retirement choices $D_{k}^{c}$, the household chooses the labor supply and retirement alternative with the highest choice-specific value function:

$$
\left(d_{i, t}^{*}\left(D_{k}^{c}\right), d_{j, t+\Delta}^{*}\left(D_{k}^{c}\right)\right)=\underset{\left(d^{F}, d^{M}\right) \in D_{k}^{c}}{\operatorname{argmax}} V_{t}^{F M}\left(d^{F}, d^{M} \mid s^{F}, s^{M}, \Psi_{i, t}, \Phi_{j, t+\Delta}\right) .
$$

The wife's and husband's optimal search intensities are given by:

$$
\begin{aligned}
& \left(s_{i, t}^{*}, s_{j, t+\Delta}^{*}\right)= \\
& \underset{\substack{s^{F} \in\left[0,1 / \chi_{i, t]}\right] \\
s^{M} \in\left[0,1 / \chi_{j, t+\Delta}\right]}}{\operatorname{argmax}}\left\{\sum_{k=1}^{K^{c}} P\left(D_{k}^{c} \mid s^{F}, s^{M}\right) V_{t}^{F M}\left(d_{i, t}^{*}\left(D_{k}^{c}\right), d_{j, t+\Delta}^{*}\left(D_{k}^{c}\right) \mid s^{F}, s^{M}, \Psi_{i, t}, \Phi_{j, t+\Delta}\right\},\right.
\end{aligned}
$$

where $P\left(D_{k}^{c} \mid s^{F}, s^{M}\right)$ is the probability of choice set $D_{k}^{c}$, given search intensities $s^{F}$ for the wife and $s^{M}$ for the husband.

Last, we split the married couple's value function into value functions for the wife and husband - as described in (16), the value functions for married women and men appear in the single household's value function. For a married woman:

$V_{t}^{F c}\left(\Psi_{i, t}, \Phi_{j, t+\Delta}\right)=\sum_{k=1}^{K^{c}} P\left(D_{k}^{c} \mid s_{i, t}^{*}, s_{j, t+\Delta}^{*}\right) V_{t}^{F c}\left(d_{i, t}^{*}\left(D_{k}^{c}\right), d_{j, t+\Delta}^{*}\left(D_{k}^{c}\right) \mid s_{i, t}^{*}, s_{j, t+\Delta}^{*}, \Psi_{i, t}, \Phi_{j, t+\Delta}\right)$,

where

$$
\begin{aligned}
& V_{t}^{F c}\left(d_{i, t}^{*}\left(D_{k}^{c}\right), d_{j, t+\Delta}^{*}\left(D_{k}^{c}\right) \mid s_{i, t}^{*}, s_{j, t+\Delta}^{*}, \Psi_{i, t}, \Phi_{j, t+\Delta}\right)= \\
& U^{F}\left(m^{*}\left(d_{i, t}^{*}\left(D_{k}^{c}\right), d_{j, t+\Delta}^{*}\left(D_{k}^{c}\right)\right), d_{i, t}^{*}\left(D_{k}^{c}\right), d_{j, t+\Delta}^{*}\left(D_{k}^{c}\right), s_{i, t}^{*}, \varepsilon_{i, t}\right)+ \\
& \delta \mathbb{E}\left[\left(1-\phi_{t+1}^{c}\right) V_{t+1}^{F s}\left(\Psi_{i, t+1}\right)+\phi_{t+1}^{c} V_{t+1}^{F c}\left(\Psi_{i, t+1}, \Phi_{j, t+\Delta+1}\right) \mid \Psi_{i, t}, \Phi_{j, t+\Delta}, d_{i, t}^{*}\left(D_{k}^{c}\right), d_{j, t+\Delta}^{*}\left(D_{k}^{c}\right)\right] .
\end{aligned}
$$

The value function for a married man may be derived in the same way. 


\section{Data and Sample}

Estimation of the model uses a semi-annual panel sample of west German singles and married couples constructed from the German Socio-Economic Panel (SOEP) survey data sets (see Wagner et al., 2007, for a description of the SOEP). The sample covers the period 1991-2005. Attention is restricted to single households in which the household head is aged 16-65 years and married couples in which both spouses are aged 16 or older and at least one spouse is age 65 or younger. We exclude individuals before their initial transition into the labor force from education. We also exclude households in which any adult household member reports being self-employed or employed by the Civil Service. The estimation sample contains 229,110 individual-half-year observations (corresponding to 135,779 household-half-year observations). Married individuals account for $84 \%$ of the observations of individuals aged 16-65 years. Table 1 reports descriptive statistics for the estimation sample. ${ }^{24}$

\begin{tabular}{|c|c|c|c|c|c|c|c|c|}
\hline \multirow{2}{*}{ Variable } & \multicolumn{2}{|c|}{ Single men } & \multicolumn{2}{|c|}{ Single women } & \multicolumn{2}{|c|}{ Married men } & \multicolumn{2}{|c|}{ Married women } \\
\hline & Obs. & Mean & Obs. & Mean & Obs. & Mean & Obs. & Mean \\
\hline Age (years) & 13959 & 39.32 & 20541 & 42.40 & 86193 & 44.06 & 89558 & 42.66 \\
\hline Education (years) & 13959 & 12.29 & 20541 & 11.76 & 86193 & 11.78 & 89558 & 11.30 \\
\hline High educe & 13959 & 0.63 & 20541 & 0.58 & 86193 & 0.56 & 89558 & 0.52 \\
\hline Experience (years) & 13959 & 14.97 & 20541 & 14.27 & 86193 & 21.37 & 89558 & 11.96 \\
\hline Full-time employe & 13959 & 0.73 & 20541 & 0.47 & 86193 & 0.78 & 89558 & 0.27 \\
\hline Part-time employed $(P T)$ & - & - & 20541 & 0.14 & - & - & 89558 & 0.27 \\
\hline Retired $(R T)$ & 13959 & 0.05 & 20541 & & & 0.05 & 89558 & 0.05 \\
\hline Non-employed $(N$ & 13959 & 0.28 & 20541 & 0.30 & 86193 & 0.17 & 89558 & 0.41 \\
\hline Assets (Euros, household) & 533 & 49,174 & 805 & 44,766 & 3415 & 142,459 & 3584 & 147,782 \\
\hline Wage (gross, hourly) & 3358 & 15.56 & 4535 & 12.71 & 24848 & 16.97 & 17270 & 11.60 \\
\hline Age $1^{\text {st }}$ Child (years) & - & - & 5394 & 11.37 & 46422 & 9.64 & 45181 & 10.03 \\
\hline
\end{tabular}

Notes: High education is defined as 12 or more years of education. Children always reside in the mother's household. Assets are right censored at 250,000 Euros for single-adult households and 500,000 Euros for married households. Descriptive statistics are for individuals aged 16-65 years.

Table 1: Descriptive statistics for the SOEP estimation sample 1991-2005.

We note four features of the sample construction. First, although the SOEP surveys are conducted annually, there is sufficient information to construct semi-annual measures of employment and retirement outcomes and household demographics. ${ }^{25}$ Second, labor

\footnotetext{
${ }^{24}$ All nominal variables are expressed in year 2000 prices using the Retail Price Index.

${ }^{25}$ In more detail, an individual is asked to report his or her labor supply status (full-time work, parttime work or non-employment) and retirement status in each month of the previous calender year. The semi-annual outcomes are defined by the individual's status in the first month of the period, i.e., January
} 
market experience is derived from a combination of retrospective information about presample behavior, and in-sample labor supply outcomes. Third, the gross hourly wage is defined as gross earnings, including overtime pay, in the month prior to the survey date divided by contractual working hours, including hours of paid overtime, during the same period. Wages are thus sampled only for those individuals who are employed in the month prior to the survey date. Fourth, we construct a measure of household assets (comprising financial, housing and durable assets) using information collected via a detailed household questionnaire administered as part of the 2002 SOEP survey. Although the wealth data is cross-sectional, it describes a broad class of assets for singles and married couples at different points in the life cycle. This information is used as an input to the estimation, providing valuable information on risk preferences (see Appendix D).

\section{Indirect Inference Estimation}

We use indirect inference to estimate the parameters of the life-cycle model (see Gourieroux et al., 1993, Smith, 1993, and Gallant and Tauchen, 1996). This simulation-based estimation method uses an auxiliary model to summarize both the estimation sample and a sample simulated using the decision rules and other equations of motion given by the life-cycle model. Parameter values for the life-cycle model are chosen to maximize the similarity between the estimation sample and the simulated sample, as viewed from the perspective of the auxiliary model.

The adopted auxiliary model contains 109 one-parameter sub-models. Each sub-model parameter pertains to wages, labor supply, household assets, or a combination thereof. The auxiliary model is designed to provide identifying information on the 46 parameters of the structural life-cycle model. Tables 8 and 9 in Appendix D describe the auxiliary model parameters and link these parameters to the identification of the parameters of the life-cycle model.

Following, e.g., Low and Pistaferri (2010) and Adda et al. (2011), we use an indirect inference estimation routine based on matching the estimates of the auxiliary model parameters obtained from the estimation sample with the corresponding estimates obtained from the simulated sample. ${ }^{26}$ Our indirect inference estimator of the parameters of the or July. An individual is classified as retired from the time that he or she reports first entering retirement. We construct the semi-annual marital status and child-related variables using retrospective information on household characteristics in January and July of each year.

${ }^{26}$ In related life-cycle models, Altonji et al. (2013) conduct indirect inference based on the quasi likelihood of the auxiliary model, and Gourieroux et al. (1993) and van der Klaauw and Wolpin (2008) base estimation on the score function of the auxiliary model. De Nardi et al. (2010) and Eckstein and Lifshitz (2011) use the closely-related Method of Simulated Moments. 
life-cycle model is defined by:

$$
\widehat{\phi}=\underset{\phi}{\operatorname{argmin}}(\widehat{\psi}-\widehat{\psi}(\phi))^{\prime} \Sigma(\widehat{\psi}-\widehat{\psi}(\phi))
$$

where $\widehat{\psi}$ denotes the vector of auxiliary model parameter estimates obtained from the estimation sample, and $\widehat{\psi}(\phi)$ denotes the auxiliary model parameters estimated using a sample simulated from the life-cycle model with parameter values $\phi$. The diagonal weighting matrix $\Sigma$ has diagonal elements equal to the inverse of the variance of each of the auxiliary model parameters, estimated using bootstrapping with clustering at the household level. We obtain standard errors using the formula provided by Gourieroux et al. (1993).

\section{Parameter Estimates, In-sample Fit and Consis- tency with Previous Studies}

\subsection{Parameter Estimates}

Estimates of the parameters of the life-cycle model are reported in Tables 2, 3 and 4 . Table 2 shows that wages are increasing in education and experience, with both dependencies being stronger for men than for women. All else equal, the market wage for men is around $50 \%$ higher than the market wage for women. Of particular relevance to the subsequent analysis, having at least 12 years of education increases the market wage by $19 \%$ for women and by $30 \%$ for men. The unobserved component of the market wage is persistent, with wage shocks being large but infrequent. Wage unobservables are positively correlated between spouses; ancillary calculations, not reported, show that the estimated correlation of 0.609 between the underlying errors in (5) that determine the evolution of spouses' wage unobservables translates into a steady state correlation of 0.200 between the spouses' contemporaneous discrete unobserved wage components, $\kappa_{i, t}$ and $\kappa_{j, t+\Delta}$.

Table 3 reports negative intercepts in the equations describing women's and men's preferences for full-time work and women's preference for part-time work. Recall, nonemployment and retirement combined form the reference category (see footnote 10). Therefore, aside from any leisure complementarities, women and men have positive utility of leisure time. In terms of magnitudes, the dis-utility of working full-time is around $45 \%$ of consumption for women aged under 50 without children, and is $10 \%$ of consumption for men aged under 50. The dis-utility of working part-time amounts to $34 \%$ of consumption for women aged under 50 without children. The distaste for full-time work is increasing in age for men and women, and women whose youngest child is aged under 3 years have 
an additional distaste for full-time work. ${ }^{27}$

Also from Table 3, the CRRA is estimated to be 2.146 for women and 2.343 for men. These figures are in line with previous studies, which typically report estimates of the CRRA in the range of 1-3 (see, e.g., Attanasio and Weber, 1995). In married couples, women receive a weight of $0.731 .^{28}$ Our estimate of the leisure complementarity parameter implies that a non-working spouse increases the utility of consumption when not working by $6.6 \%$. Table 4 shows that the probability of a job offer, conditional on search intensity, is decreasing in age, increasing in education, and is lower for married individuals than for singles.

\begin{tabular}{|c|c|c|}
\hline & Women & Men \\
\hline Intercept $\left(\beta_{1}^{F}, \beta_{1}^{M}\right)$ & $\begin{array}{l}2.343 \\
(0.006)\end{array}$ & $\begin{array}{l}2.818 \\
(0.008)\end{array}$ \\
\hline $\operatorname{Exp} / 40\left(\beta_{2}^{F}, \beta_{2}^{M}\right)$ & $\begin{array}{l}0.056 \\
(0.012)\end{array}$ & $\begin{array}{l}0.160 \\
(0.018)\end{array}$ \\
\hline Education $\geq 12$ years $\left(\beta_{3}^{F}, \beta_{3}^{M}\right)$ & $\begin{array}{l}0.193 \\
(0.014)\end{array}$ & $\begin{array}{l}0.301 \\
(0.017)\end{array}$ \\
\hline $\mathrm{P}\left(\kappa_{t}=1 \mid \kappa_{t-1}=1\right)\left(\Phi\left(\theta_{1}^{F}\right), \Phi\left(\theta_{1}^{M}\right)\right)$ & $\begin{array}{l}0.990 \\
(0.001)\end{array}$ & $\begin{array}{l}0.954 \\
(0.005)\end{array}$ \\
\hline $\mathrm{P}\left(\kappa_{t}=1 \mid \kappa_{t-1}=0\right)\left(\Phi\left(\theta_{0}^{F}\right), \Phi\left(\theta_{0}^{M}\right)\right)$ & $\begin{array}{l}0.028 \\
(0.004)\end{array}$ & $\begin{array}{l}0.034 \\
(0.004)\end{array}$ \\
\hline Loading on persistent unobservable $\left(\beta_{4}^{F}, \beta_{4}^{M}\right)$ & $\begin{array}{l}0.893 \\
(0.019)\end{array}$ & $\begin{array}{l}0.713 \\
(0.012)\end{array}$ \\
\hline Between-spouse correlation of persistent wage shocks $(\varrho)$ & \multicolumn{2}{|c|}{$\begin{array}{l}0.609 \\
(0.053)\end{array}$} \\
\hline Standard deviation of measurement error $\left(\sigma_{\nu F}, \sigma_{\nu M}\right)$ & $\begin{array}{l}0.014 \\
(0.002)\end{array}$ & $\begin{array}{l}0.019 \\
(0.004)\end{array}$ \\
\hline
\end{tabular}

Notes: Standard errors in parentheses. $\Phi()$ is the standard normal distribution function. Table 2: Wage equation.

\footnotetext{
${ }^{27}$ The positive preference increments arising from the presence of young children derive from the relative flatness of the budget constraint for many women. This flatness of the budget constraint reflects the combined effects of the withdrawal of Social Assistance benefits against other sources of household income, child-care costs and the low market wages for women.

${ }^{28} \mathrm{~A}$ structural interpretation of this parameter is unavailable because the parameter value partly reflects the scaling of women's and men's utility functions.
} 
$\underline{\text { State-specific taste for consumption: }}$

Full-time employment: Intercept

$\left(\eta_{1, F}^{F}, \eta_{1, F T}^{M} \eta_{2, F T}^{F}, \eta_{2, F T}^{M}\right)$ Youngest child aged $<3$

$3 \leq$ Youngest child aged $<6$

$\begin{array}{cc}-0.607 & -0.105 \\ (0.014) & (0.051) \\ -0.408 & - \\ (0.021) & \\ 0.251 & - \\ (0.082) & \\ -0.326 & -0.352 \\ (0.038) & (0.013) \\ 0.106 & -1.443 \\ (0.055) & (0.033)\end{array}$

Part-time employment: Intercept

$-0.415$

$(0.021)$

$\left(\eta_{1, P T}^{F}, \eta_{2, P T}^{F}\right)$ Youngest child aged $<3$

0.169

$(0.025)$

$3 \leq$ Youngest child aged $<6$

0.734

$(0.095)$

Age $\geq 50$

$-0.250$

$(0.045)$

Age $\geq 50 \times$ Married

0.301

$(0.058)$

Further preference parameters:

\section{$\operatorname{CRRA}\left(\rho^{F}, \rho^{M}\right)$}

Scale of preference shocks for single individuals $\left(\varsigma_{F S}, \varsigma_{M S}\right)$

Scale of preference shocks for married individuals $\left(\varsigma_{F C}, \varsigma_{M C}\right)$

Between spouse leisure complementarity $\left(\eta_{3}\right)$

Weight on female spouse $(\alpha)$
$2.146 \quad 2.343$

(0.116) $\quad(0.045)$

$0.553 \quad 0.753$

$(0.029) \quad(0.032)$
0.765

$\begin{array}{ll}0.765 & 1.320 \\ (0.020) & (0.084)\end{array}$

0.064

$(0.027)$

0.731

(0.014)

Notes: Standard errors in parentheses.

Table 3: Preference parameters. 


\begin{tabular}{rcc}
\hline \hline & Women & Men \\
\cline { 3 - 4 } & & \\
Intercept $\left(\chi_{1}^{F}, \chi_{1}^{M}\right)$ & -0.930 & -0.971 \\
& $(0.048)$ & $(0.036)$ \\
Age $\geq 50\left(\chi_{2}^{F}, \chi_{2}^{M}\right)$ & -2.506 & -2.593 \\
& $(0.394)$ & $(0.136)$ \\
Education $\geq 12$ years $\left(\chi_{3}^{F}, \chi_{3}^{M}\right)$ & 0.263 & 0.235 \\
Married $\left(\chi_{4}^{F}, \chi_{4}^{M}\right)$ & -0.685 & $(0.048)$ \\
& $(0.037)$ & $(0.0893$ \\
\hline \hline
\end{tabular}

Notes: Standard errors in parentheses.

Table 4: Job offer probability.

\section{$5.2 \quad$ In-sample Goodness of Fit}

We assess in-sample fit by examining the model's ability to match the 109 auxiliary model parameters, which summarize the patterns of labor supply, wages and wealth seen in the estimation sample. Tables 10-13 in Appendix E shows that the estimated model obtains a close fit to the auxiliary model parameter estimates obtained from the estimation sample; for instance, in the estimation sample $76 \%$ of single men aged under 50 are employed while the corresponding employment rate in the simulated sample is $75 \%$, average wealth for married couples where the husband is aged 50 or older is 197,000 Euros in the estimation sample and 192,000 Euros in the simulated sample, and the correlations between log wages in consecutive years for women and men are 0.11 and 0.12 , respectively, in the estimation sample, compared to 0.13 and 0.12 in the simulated sample. The estimated model also replicates closely the joint distribution of the labor supply outcomes of wives and husbands, e.g., in the estimation sample we observe the wife working full-time and the man being non-employed in $4 \%$ of married couples while the model implies a figure of $3 \%$, and the model and estimation sample concur on the wife being non-employed and the husband working full-time in $33 \%$ of married couples.

\subsection{Consistency with Previous Studies}

Following, e.g., Todd and Wolpin (2006) and Low and Pistaferri (2010), we assess the plausibility of the estimated model by comparing the model's implications with findings from related studies. In particular, we show that the estimated model implies that employment depends on key parameters of the Unemployment Insurance system in a way that is consistent with findings from reduced-form studies that exploit plausibly exogenous variation in benefit rules. These quantities are not targeted in our estimation routine, and this exercise therefore provides external support for the estimated model. Summarizing briefly, prior work suggests that a one-week increase in the Unemployment Insurance 
entitlement period increases the time until re-employment by $0.05-0.15$ weeks. ${ }^{29}$ Regarding the level of benefits, reduced-form evidence is less plentiful and more mixed. Prior research suggests that a 10 percentage point increase in the replacement rate increases the time until re-employment by $0.5-1.5$ weeks, and reports elasticities ranging from 0.15 to above 2 (Card et al., 2012, survey recent findings). ${ }^{30}$

Based on the estimated model, we derive marginal effects mirroring those reported in the reduced-form literature. Specifically, using the Unemployment Insurance system described above in Section 2.6.2, we simulate inflow samples of Unemployment Insuranceeligible individuals entering non-employment at ages 20,30 and 40 years. Subsequent employment outcomes are simulated under a baseline regime and under two counterfactual regimes. In the baseline regime, the Unemployment Insurance system is unchanged - the initial entitlement period is 12 months for individuals entering non-employment before age 45 , and the replacement rate is $60 \%$ for individuals without children (or $67 \%$ for those with children). In the first counterfactual regime, there is an unanticipated increase of 6 months in the initial entitlement period. In the second counterfactual regime, there is an unanticipated increase in the replacement rate of 10 percentage points, occurring at the start of the non-employment spell. Panel A in Table 5 summarizes the implications of the estimated model with respect to the initial entitlement period. ${ }^{31}$ The model predicts

\footnotetext{
${ }^{29}$ For example, looking at Germany and using a sample period similar to our study, Schmieder et al. (2012, Table II) exploit age-based discontinuities and find that a one-week extension of the initial entitlement period increases the time until re-employment by $0.1-0.13$ weeks for individuals in their $40 \mathrm{~s}$. Using a difference-in-differences approach to estimate the same quantity for Austria, Lalive et al. (2006, Table 5) report values of 0.05 weeks at age 40-49 and 0.1 weeks at age 50 and above. Also see the surveys by Atkinson and Micklewright (1991) and Tatsiramos and van Ours (2014).

${ }^{30}$ Using a difference-in-differences approach and data from Austria, Lalive et al. (2006, Table 5) report that a 6 percentage point increase in the replacement rate increases the average duration of nonemployment 0.38 weeks. Using a regression kink design, Landais (forthcoming) finds elasticities for the duration of benefit claims with respect to the replacement rate of between $0.2-0.7$ for the US. Card et al. (2012) report elasticities for the time until re-employment with respect to the replacement rate for Austria ranging from 1.4 to above 2. There is little evidence on replacement rate effects for Germany. One exception is Hunt (1995) who finds that a cut of the replacement rate in the 1980s for individuals without children increased the exit rate from unemployment into retirement. Early studies estimated the employment effects of the level and duration of Unemployment Insurance benefits without appeal to exogenous policy changes, discontinuities or other quasi-natural sources of variation. Using US data, Katz and Meyer (1990) find that a one-week extension of the initial entitlement period increased the time until re-employment by $0.16-0.20$ weeks. Concerning the same quantity, Moffitt and Nicholson (1982) report a figure of 0.1 weeks for the US, and Ham and Rea (1987) find effects in the range of 0.26-0.33 weeks for Canada. Katz and Meyer (1990) report that a 10 percentage point increase in the replacement rate increases the duration until re-employment by $1.2-1.5$ weeks.

${ }^{31}$ Similar to Schmieder et al. (2012), we rescale the employment effect of a 6 month increase in the initial entitlement period to obtain the effect of a one-week benefit extension.
} 
that a one-week increase in the initial entitlement period increases the duration until reemployment by 0.09-0.14 weeks. Consistent with Schmieder et al. (2012), the employment effects of benefit extensions vary little by gender or age. Panel B in Table 5 shows that a 10 percentage point increase in the replacement rate is predicted to increase the duration until re-employment by $0.5-1.6$ weeks, with effects at ages 30 and 40 years being slightly larger for men than for women.

\begin{tabular}{ccc}
\hline \hline & \multicolumn{3}{l}{ Age at start of non-employment spell (years) } \\
\cline { 2 - 3 } 20 & 30 & 40 \\
\hline
\end{tabular}

Panel A: Effect of one-week increase in the initial entitlement period on average weeks until reemployment:

$\begin{array}{clll}\text { Women } & 0.095 & 0.126 & 0.121 \\ \text { Men } & 0.091 & 0.126 & 0.139\end{array}$

Panel B: Effect of 10 percentage point increase in the replacement rate on average weeks until reemployment:

$\begin{array}{clll}\text { Women } & 1.256 & 0.737 & 0.549 \\ \text { Men } & 1.154 & 0.933 & 0.982\end{array}$

Notes: Results are based on 135,195 simulated non-employment spells. Spells are right censored at 30 months. Only eligible individuals are included. To ensure comparability with the literature, which generally reports effects for the gross replacement rate, our net replacement rate effects have been scaled by $(1-\tau)^{-1}$ where $\tau$ is the average payroll deduction rate of 0.37 .

Table 5: Effect of Unemployment Insurance on the duration until reemployment.

As a further plausibility check, we show that the model-implied effect of Unemployment Insurance on the timing of exits from non-employment is in line with previouslydocumented patterns. ${ }^{32}$ Consistent with the empirical results of Lalive et al. (2006), Figure 2 shows that the effect of an increase in the initial entitlement period from 12 to 18 months is concentrated around the time of benefit exhaustion. In contrast, and again consistent with Lalive et al. (2006), the model implies that the employment effect of a

\footnotetext{
${ }^{32}$ Given the semi-annual decision making frequency in the model, exits from non-employment are possible only at 6 month intervals.
} 
10 percentage point increase in the replacement rate occurs mainly during the period of Unemployment Insurance-covered non-employment, i.e., during the first 12 months of the non-employment spell.

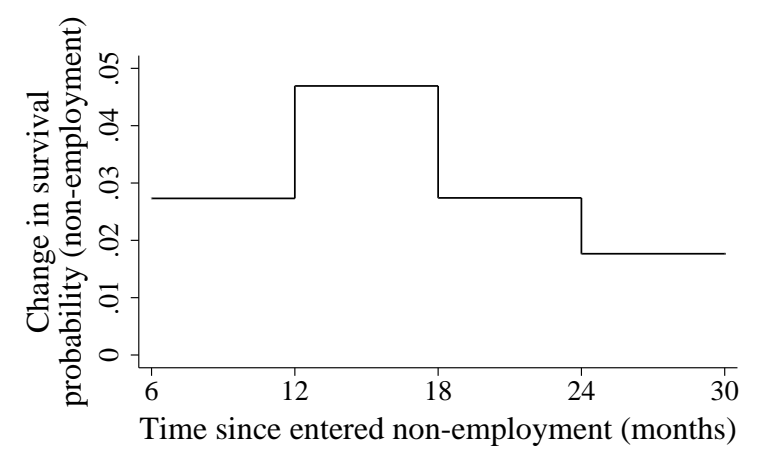

(a) Initial entitlement period extended from 12 to 18 months.

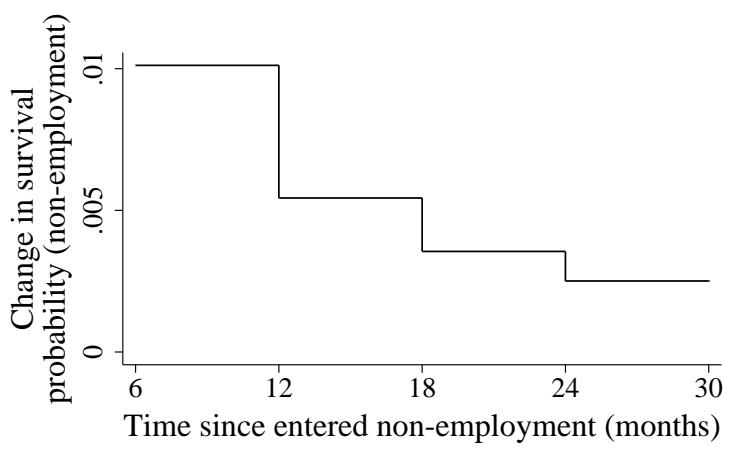

(b) Replacement rate increased by 10 percentage points.

Notes: Survivor functions are estimated using a pooled inflow sample of Unemployment Insurance-eligible individuals entering non-employment at ages 20, 30 and 40 years.

Figure 2: Effect of Unemployment Insurance on the non-employment survivor function.

\section{Optimal Social Assistance and Unemployment Insurance}

\subsection{Overview}

We use the estimated life-cycle model to provide empirical evidence about the behavioral effects, welfare effects and optimal design of Social Assistance and Unemployment Insurance when individuals may be single or married. We also explore how the family context impacts on the optimal generosities of Social Assistance and Unemployment Insurance. In these analyses, we vary program generosities through revenue neutral changes in the Unemployment Insurance replacement rate and in the Social Assistance income floor.

Before we turn to the empirical analysis, we briefly discuss the insurance, incentive and redistributive effects of Social Assistance and Unemployment Insurance. We first abstract from redistributive effects, and consider the design of social insurance and assistance programs for a society of single women or single men who share the same level of education. In this case, optimal benefit generosities are determined by trading off the provision of insurance against the moral hazard effects on search behavior and on voluntary quits. Social Assistance and Unemployment Insurance have different insurance 
and incentive effects, due to differences in the ways that the programs are targeted. The optimal combination of these programs, therefore, may involve both Social Assistance and Unemployment Insurance. ${ }^{33}$

In more detail, Unemployment Insurance provides temporary earnings-related assistance to individuals who recently left employment, and therefore is effective at mitigating the short-term effects of job loss, irrespective of an individual's position in the earnings distribution. However, Unemployment Insurance encourages voluntary quits and discourages search during the period of benefit receipt. Reflecting the earnings-related nature of the benefits, both moral hazard effects operate throughout the wage distribution. Social Assistance, meanwhile, guarantees a permanent universal minimum household income, and is thus effective at mitigating both the short-term and the long-term effects of job loss for low-wage individuals. Like Unemployment Insurance, Social Assistance encourages voluntary quits and discourages search. However, Social Assistance has long-term disincentive effects on search, because benefits are not time-limited. Meanwhile, the adverse incentive effects of Social Assistance on search behavior and voluntary quits are largely limited to low-wage individuals because the income floor is universal, rather than earnings-related.

Reintroducing redistributive concerns, the effect of education on wages and job destructions generates a redistributive motive for social programs. Both Social Assistance and Unemployment Insurance are redistributive; however, by targeting directly low-income individuals, Social Assistance redistributes strongly toward low-educated individuals. Due to its link with earnings and the time-limited nature of the benefits, Unemployment Insurance is less redistributive than Social Assistance.

One contribution of this paper is to shed light on the optimal design of Social Assistance and Unemployment Insurance while recognizing the family context. The family unit is relevant to program design partly because the insurance, incentive and redistributive effects of Social Assistance and Unemployment Insurance depend on marital status. As for singles, Unemployment Insurance provides married individuals with short-term partial earnings replacement following job loss, and search behavior and voluntary quits are subject to moral hazard effects. However, because Unemployment Insurance benefits are paid to non-employed individuals with a working spouse, the presence of married couples weakens the redistributive effect of Unemployment Insurance. Social Assistance benefits, meanwhile, are restricted to individuals who would otherwise be poor after accounting for both spouses' earnings. Social Assistance, therefore, does not provide insurance against job loss when the spouse is employed and, correspondingly, the moral hazard effects of Social Assistance on search and voluntary quits are weaker for married individuals than for

\footnotetext{
${ }^{33}$ For discussion of the optimal Unemployment Insurance replacement rate when ex ante identical individuals can save and borrow, either via perfect capital markets or with some restrictions, see Flemming (1978), Acemoglu and Shimer (1999), Chetty (2008) and Lentz (2009).
} 
singles. However, because the benefits are focused on households rather than individuals, Social Assistance remains strongly redistributive in the presence of married couples.

Differences in risk exposure and in intra-household insurance by marital status constitute further reasons for the optimal generosities of Social Assistance and Unemployment Insurance to depend on the family circumstances of the population. In married couples, wage risk and employment risk are pooled, and additional intra-household insurance is available from shared wealth and from family labor supply. Insurance from family labor supply arises from both an income effect - the spouse may have earnings that persist in the face of the individual's own wage or employment shock - and an adjustment effect a married couple may adjust one spouse's labor supply in response to the other spouse's wage and employment shocks.

\subsection{Welfare Metric}

We evaluate the welfare implications of policy reforms using a weighted average of moneymetric measures of women's and men's life-time gains. Formally, the welfare value of a move from the baseline environment, specifically the year 2000 Social Assistance and Unemployment Insurance system, to an alternative policy environment, $A$, is defined as:

$$
W_{A}=\Upsilon \phi_{A}^{F} P_{0}^{F}+(1-\Upsilon) \phi_{A}^{M} P_{0}^{M}
$$

where $\phi_{A}^{F}$ and $\phi_{A}^{M}$ denote the per-period money-metric values to women and men of a move to environment $A$ (further details are provided below), $P_{0}^{F}$ and $P_{0}^{M}$ denote the average discounted duration until death for women and men, measured at entry into the labor force from education, and $\Upsilon$ may be interpreted as either the share of women in the population or the social planner's weight on women's welfare gains. Given approximately equal shares of women and men in the population under study, we focus on the results for $\Upsilon=0.5$, and interpret the resulting welfare value as the average per-person value of a move from the baseline system to the alternative policy environment.

The key inputs to the welfare value are the per-period money metric values of the policy change, $\phi_{A}^{F}$ for women and $\phi_{A}^{M}$ for men. Similar to the equivalent variation-based measure used in Low et al. (2010), $\phi_{A}^{F}$ and $\phi_{A}^{M}$ correspond to the per-period adjustments in baseline consumption required to equalize women's and men's expected discounted life-time utilities across the baseline and alternative environments. Formally, $\phi_{A}^{F}$ and $\phi_{A}^{M}$ solve:

$$
\begin{array}{r}
\mathbb{E}\left[\sum_{\tau=\underline{t}_{i}}^{\bar{T}^{F}} \delta^{\left(\tau-\underline{t}_{i}\right)} U^{F}\left(m_{i, j, \tau}^{A}, d_{i, \tau}^{A}, d_{j, \tau+\Delta}^{A}, s_{i, \tau}^{A}, \varepsilon_{i, \tau}\right) \mid \text { Env. } A\right]= \\
\mathbb{E}\left[\sum_{\tau=\underline{t}_{i}}^{\bar{T}^{F}} \delta^{\left(\tau-\underline{t}_{i}\right)} U^{F}\left(m_{i, j, \tau}^{B}+\phi_{A}^{F}+\phi_{A}^{M} \operatorname{Married}_{i, \tau}, d_{i, \tau}^{B}, d_{j, \tau+\Delta}^{B}, s_{i, \tau}^{B}, \varepsilon_{i, \tau}\right) \mid \text { Env. } B\right],
\end{array}
$$


along with the corresponding equality for men. Here, $\underline{t}_{i}$ denotes the period of woman $i$ 's entry into the labor force from education, Env. $B$ refers to the baseline environment and Env. $A$ refers to the alternative environment. Note, because consumption is a public good within the household, the married woman's utility is impacted by the consumption increment for men, and vice versa. The expectations in (29) and in the corresponding condition for men are taken with respect to education and with respect to all shocks, including wage shocks and job destructions. In this way, the per-period consumption increments $\phi_{A}^{F}$ and $\phi_{A}^{M}$ capture individuals' preferences for insurance and redistribution.

\subsection{Social Assistance}

We assess the behavioral effects and optimal generosity of Social Assistance by considering revenue neutral, proportional adjustments of the baseline Social Assistance income floor. In doing so, we vary the overall generosity of Social Assistance while holding fixed the economy's net budget position and holding fixed the baseline relationship between the Social Assistance income floor and household composition (see Appendix C). Throughout this exercise, the Unemployment Insurance replacement rate is held at the baseline level of $60 \% .^{34}$

Figure 3(a) shows that wealth accumulation increases as the Social Assistance income floor is decreased below the baseline level, reflecting substitution between intra-household insurance from savings and social insurance from Social Assistance. Similarly, Figures 3(b) and 3(c) show that moving from the baseline Social Assistance system to a less generous system increases the employment rates of single and married women and men, representing the combined effects of stronger search incentives and weaker incentives to voluntarily quit employment. However, the magnitude of the overall employment responses to marginal cuts in Social Assistance is decreasing in the benefit generosity, and is negligible at low levels of benefit generosity. Further, the employment rate of married women is not strongly dependent on the generosity of Social Assistance; this pattern arises because the withdrawal of Social Assistance benefits against the spouse's earnings leaves most married women without support from Social Assistance, irrespective of their behavior.

Figure 3(d) shows that the optimal Social Assistance income floor is $59 \%$ of the baseline

\footnotetext{
${ }^{34}$ For each policy environment, we ensure revenue equivalence to the baseline system by imposing a flat-rate tax or subsidy on net household income from earnings, interest on wealth, child benefits and Unemployment Insurance benefits. Revenue equivalence refers to the same aggregate value of taxes plus Social Security Contributions, less Social Assistance, Unemployment Insurance, child and public pension benefits. Imposing revenue equivalence in this way ensures that the Unemployment Insurance replacement rate continues to be the fraction of net earnings replaced by Unemployment Insurance benefits. In all optimality exercises, we apply the same replacement rate to individuals with and without dependent children.
} 


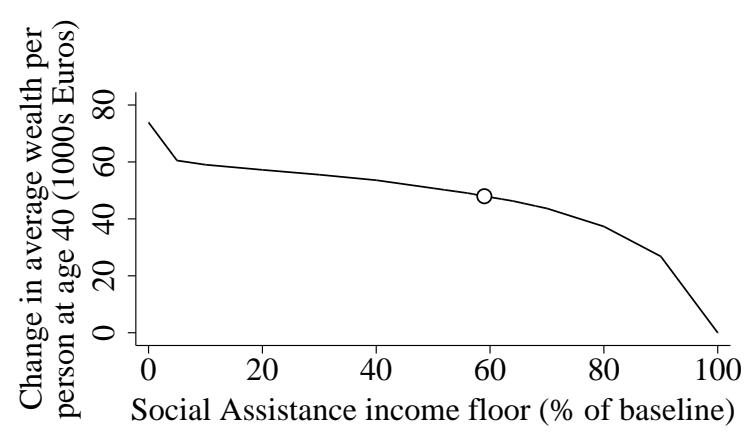

○ Optimal policy

(a) Wealth.

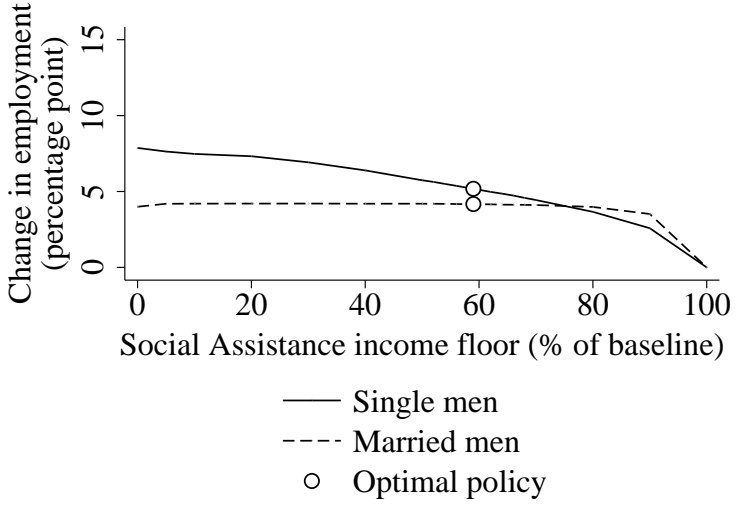

(c) Male employment.

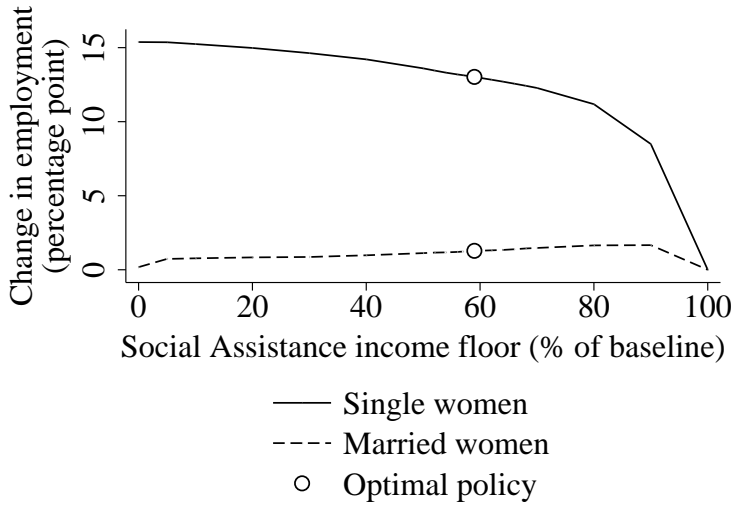

(b) Female employment.

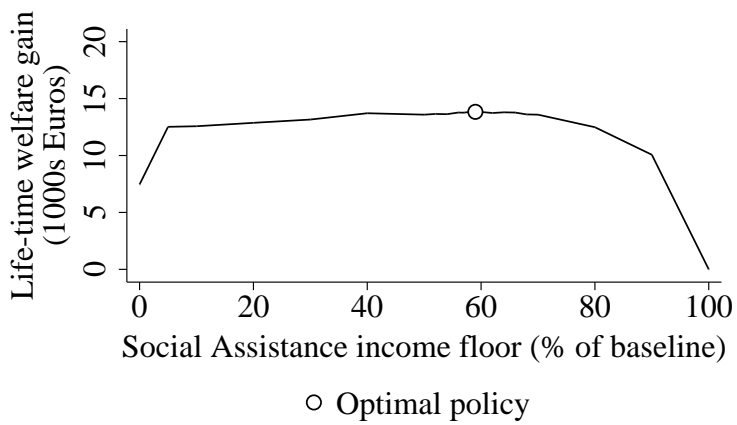

(d) Welfare.

Notes: An additional flat-rate tax or subsidy on net household income from earnings, interest on wealth, child benefits and Unemployment Insurance benefits ensures that all policy environments are revenue equivalent to the baseline system. Income floors above $100 \%$ of the baseline generosity (in conjunction with an Unemployment Insurance replacement rate of 60\%) are prohibitively expensive, i.e., there is no additional flat-rate tax on net income from earnings, interest on wealth, child benefits and Unemployment Insurance benefits that imposes revenue equivalence to the baseline environment.

Figure 3: Wealth, employment and welfare by Social Assistance income floor.

level, meaning that, e.g., a married couple with two pre-school aged children receives a maximum of 966 Euros per month in Social Assistance benefits, instead of the baseline maximum of 1,638 Euros per month. The life-time welfare gains from a move from the baseline system to the optimal Social Assistance system average 13,636 Euros per person, and represent an increase of $2.91 \%$ in the present value of average life-time consumption. Increasing the weight on low income individuals in the social welfare function is likely to increase the optimal generosity of Social Assistance. The analysis in Section 6.6 speaks to this question by calculating optimal policies for different education groups. 


\subsection{Unemployment Insurance}

We explore the behavioral and welfare effects of Unemployment Insurance by making revenue neutral adjustments to the replacement rate while maintaining the baseline Social Assistance system. ${ }^{35}$ Figure 4(a) shows that wealth accumulation is decreasing in the generosity of Unemployment Insurance. However, conditional on the welfare gain, wealth accumulation is less sensitive to Unemployment Insurance than to Social Assistance. Figures 4(b) and 4(c) show that the employment rates of single and married women and men are decreasing in the replacement rate. In contrast to the findings for Social Assistance, the employment rate of married women increases markedly in response to cuts in the replacement rate, reflecting that Unemployment Insurance benefits are not contingent on the spouse's earnings. Also in contrast to Social Assistance, at both low and high levels of benefit generosity, marginal cuts in the Unemployment Insurance replacement rate lead to appreciable increases in employment for all demographic groups.

Figure $4(\mathrm{~d})$ shows that a replacement rate of $0 \%$ maximizes the average per-person welfare gain. The life-time welfare gains from this reform average 11,624 Euros per person, or $2.53 \%$ of the average present value of life-time consumption. Three factors are of particular importance in driving the optimal replacement rate to $0 \%$. First, given the baseline Social Assistance system, the redistributive and insurance effects for Unemployment Insurance are limited. In Section 6.5 we show that a non-zero replacement rate may be optimal in the presence of a less generous Social Assistance system. Second, the moral hazard effect of Unemployment Insurance on the employment rate operates even at low levels of benefit generosity. Third, reflecting the administration of Unemployment Insurance in Germany (see footnote 18), benefits are available to individuals who voluntarily quit their jobs. The moral hazard effects of Unemployment Insurance thus extend beyond search behavior, and include distorted incentives encouraging selection into receiving Unemployment Insurance benefits.

In principle, redistributive concerns may contribute to the finding of an optimal replacement rate of $0 \%$, particularly since Unemployment Insurance is a relatively weak redistributive device in the presence of married individuals. However, the results reported in Section 6.6 show that this finding is not driven by education-based redistributive concerns or by factors that are specific to married couples.

\footnotetext{
${ }^{35}$ Our focus on the replacement rate follows, e.g., Chetty (2008), Lentz (2009) and Landais (forthcoming). When interpreting our results, it is helpful to note that the previous literature on optimal Unemployment Insurance generally abstracts from wage heterogeneity (see, e.g., Baily, 1978, and Chetty, 2006, and subsequent applications). Without wage heterogeneity, there is no distinction between earnings-related and non-earnings-related benefits, and redistributive motives for social programs are absent. Comparisons with our results are therefore not immediate.
} 


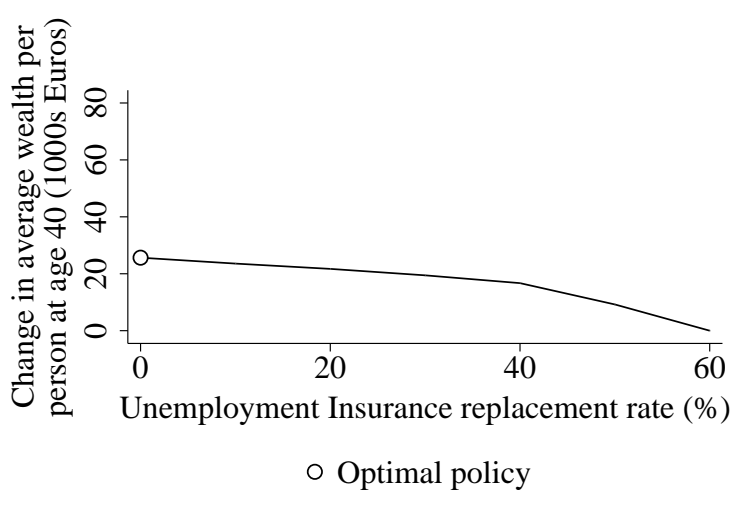

(a) Wealth.

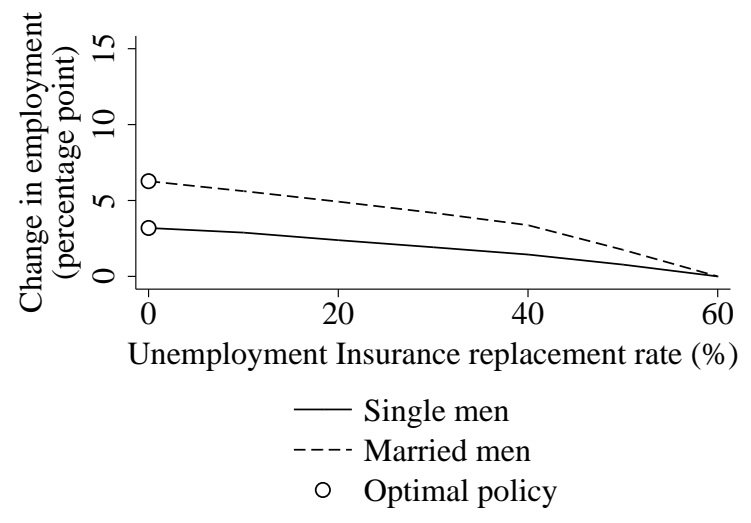

(c) Male employment.

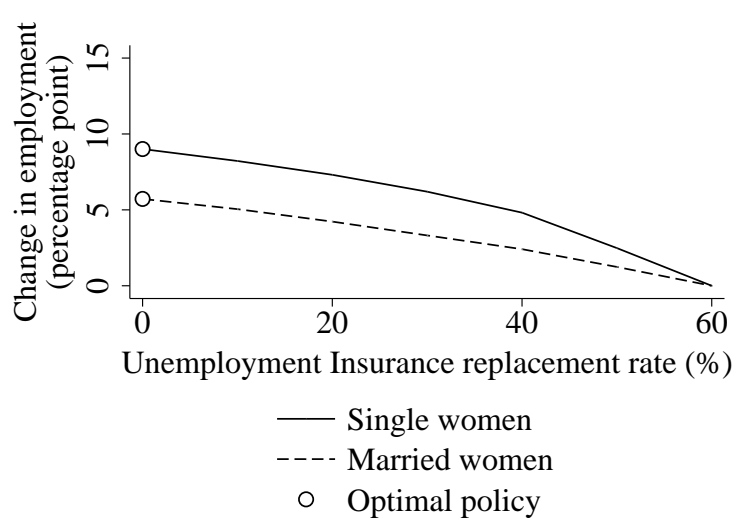

(b) Female employment.

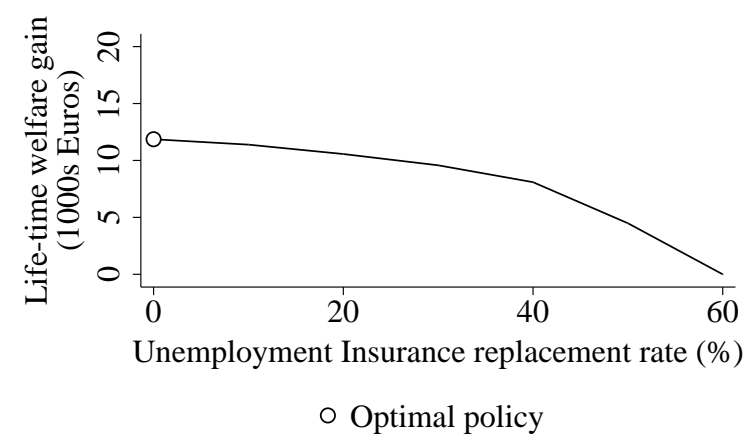

(d) Welfare.

Notes: See notes to Figure 3.

Figure 4: Wealth, employment and welfare by Unemployment Insurance replacement rate.

\subsection{Optimal Mix of Social Assistance and Unemployment Insurance}

In this section, we move beyond considering social insurance and assistance programs in isolation from each other, and turn our attention to the optimal combination of Social Assistance and Unemployment Insurance generosities. Figure 5 shows the average life-time welfare gains associated with Unemployment Insurance replacement rates of $0 \%, 20 \%$, $60 \%$ (the baseline generosity) and 80\%, and Social Assistance generosities ranging from $5 \%$ to $100 \%$ of the baseline level. ${ }^{36}$ The optimal policy mix combines a Social Assistance

\footnotetext{
${ }^{36}$ We refrain from illustrating the welfare effects associated with Social Assistance income floors below $5 \%$ of the baseline level because the average life-time welfare change becomes strongly negative as both the replacement rate and the Social Assistance income floor approach zero. In additional unreported analysis, we computed welfare gains from replacement rates of 10\%, 30\%, 40\%, $50 \%$ and $70 \%$ in conjunction with Social Assistance generosities ranging from $0 \%$ to $100 \%$ of the baseline level. All of these additional
} 
system that is $66 \%$ as generous as the baseline system with a $0 \%$ Unemployment Insurance replacement rate. The average life-time welfare gain from a move to this combination of benefit generosities is 19,276 Euros per person - an increase of around 6,000 Euros per person on the gain obtained from optimizing the generosity of Social Assistance alone, and an increase of around 7,800 Euros per person on the gain obtained from optimizing the generosity of Unemployment Insurance alone. This result expands the findings of Low et al. (2010), and shows that the lower baseline valuation of Unemployment Insurance, compared to the baseline valuation of social assistance programs, translates into a minimal optimal generosity for Unemployment Insurance, while optimal social protection instead operates primarily through permanent universal assistance-orientated benefits.

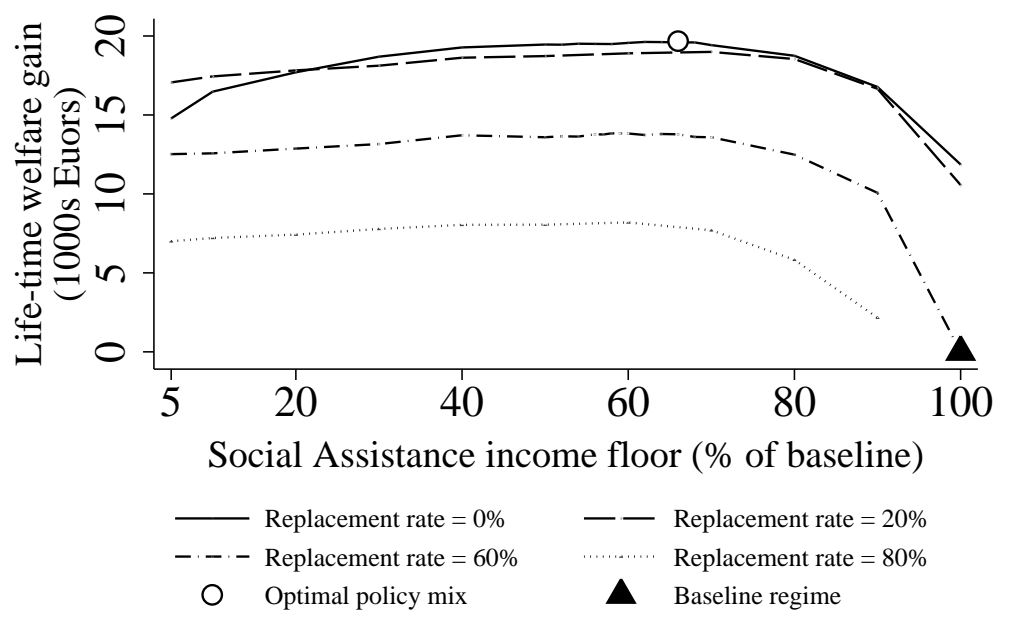

Notes: See footnote 36 and notes to Figure 3.

Figure 5: Life-time welfare gains from combined adjustments in the generosities of Social Assistance and Unemployment Insurance.

Figure 5 illustrates two related aspects of interdependence between Social Assistance and Unemployment Insurance. First, the optimal Social Assistance generosity is $66 \%$ of the baseline level when the Unemployment Insurance replacement rate is $0 \%$, while, as discussed in Section 6.3, the optimal Social Assistance generosity takes the lower value of $59 \%$ of the baseline level when the Unemployment Insurance replacement rate is fixed at $60 \%$. Second, broadly in line with the findings of Saporta-Eksten (2014), at low Social Assistance generosities, the optimal Unemployment Insurance replacement rate is above zero - e.g., an optimal replacement rate of $20 \%$ applies when the Social Assistance income floor is fixed at either $5 \%$ or $10 \%$ of the baseline level.

program combinations were found to have less favorable welfare effects than the most favorable of the illustrated policies. 
Our findings suggest that the optimal combination of Social Assistance and Unemployment Insurance differs fundamentally from the current German system that, like benefit systems in many continental European counties, contains generous insurance-motivated earnings-related benefits. Instead, our optimal policy rule shares many features with more assistance-orientated systems, such as the benefit systems in the United Kingdom and in several Scandinavian countries. In the spirit of our results on the optimal policy mix, the United Kingdom does not have earnings-related Unemployment Insurance benefits; instead a non-employed individual may receive Jobseeker's Allowance, which provides a benefit that is unrelated his or her history of earnings and employment. ${ }^{37}$

\subsection{Optimal Policy and the Family Context}

As a final step, we explore the impact of the family context on the optimal design of social insurance and assistance programs. To this end, we compare optimal program generosities for a society of always-single individuals and for a society in which individuals marry and divorce with the empirical probabilities (see Appendix A.1). In our analysis, we explore the impact of the family on the optimal single-program generosities, i.e., the optimal Unemployment Insurance replacement rate, given the baseline Social Assistance system, and vice versa. We also consider the role of the family in driving the optimal mix of Social Assistance and Unemployment Insurance generosities. We disaggregate our analysis by education, and this informs on how education-based redistributive concerns and education-based variation in the demand for social insurance and assistance play into the optimal policy calculations.

Table 6 presents optimal program generosities according to the distributions of education and marriage in the population. Panel A shows that the optimal single-program generosity of Social Assistance for a society of always-single low-educated individuals is $80 \%$ of the baseline level, while a lower optimal single-program generosity of $66 \%$ of the baseline level applies to a society of always-single high-educated individuals. This difference by education reflects that high-educated individuals place a relatively low value on insurance from Social Assistance, due to their relatively high wages, low job destruction risk and high likelihood of being eligible for generous Unemployment Insurance benefits. When low-educated and high-educated always-single individuals are combined into one society a redistributive motive arises and the optimal single-program generosity of Social Assistance is $72 \%$ of the baseline level. The optimal single-program Unemployment Insurance replacement rate is $0 \%$ for single individuals, irrespective of education. Turning to the optimal mix of Social Assistance and Unemployment Insurance generosities, we find that, irrespective of education, the optimal combination of benefits for single individuals

\footnotetext{
${ }^{37}$ The withdrawal of Jobseeker's Allowance against other income sources depends on the individual's employment history.
} 
entails moderately generous Social Assistance and no Unemployment Insurance. ${ }^{38}$

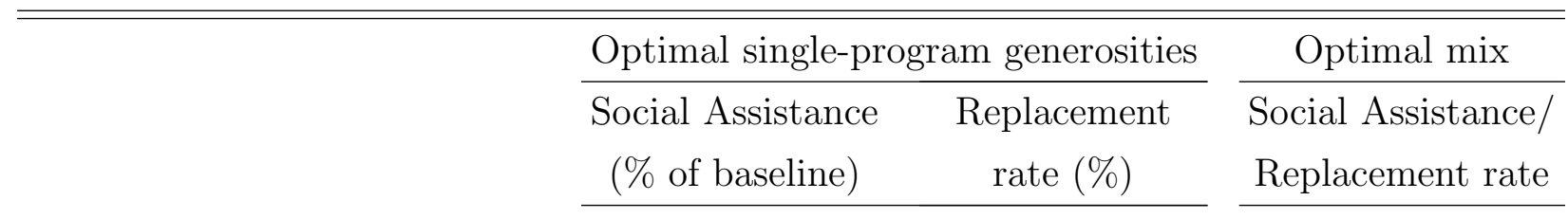

Panel A: Single individuals only (zero probability of marriage):

Low educated individuals

High educated individuals

High and low educ. individuals
80

66

72
0

0

0
$81 / 0$

$80 / 0$

$84 / 0$

Panel B: Single and married individuals (empirical marriage and divorce probabilities):

Low educated individuals

High educated individuals

High and low educ. individuals
66

58

59
0

0

0
$64 / 10$

$67 / 10$

$66 / 0$

Notes: Optimal single-program generosities refer to the optimal Social Assistance generosity, given baseline Unemployment Insurance, and vice versa. Optimal mix refers to the welfare-maximizing combination of the Social Assistance income floor, expressed as a percentage of the baseline, and the Unemployment Insurance replacement rate, expressed as a percentage. In Panel B, where marriage and divorce occur with the empirical probabilities, $68 \%$ of low educated individuals and $60 \%$ of high educated individuals aged 16-65 years reside in married households. In the mixed education society with marriage and divorce, individuals match assortatively as described in Appendix A.2.

Table 6: Effect of the family on the optimal generosities of Social Assistance and Unemployment Insurance.

A comparison of Panels A and B of Table 6 shows that introducing marriage and divorce markedly reduces the optimal single-program generosities of Social Assistance.

\footnotetext{
${ }^{38}$ For always-single low-educated individuals, the optimal generosity of Social Assistance is essentially invariant with respect to the Unemployment Insurance replacement rate, reflecting that Social Assistance is withdrawn one-for-one against Unemployment Insurance benefits and, for low-wage individuals, has a similar value to Unemployment Insurance benefits. In contrast, the optimal generosity of Social Assistance for high-educated individuals depends strongly on the Unemployment Insurance replacement rate, which reflects that the baseline Unemployment Insurance system provides insurance to the high educated, beyond that provided by Social Assistance. Redistributive concerns drive the welfare-maximizing generosity of Social Assistance in the optimal mix above the education-specific optimal generosities.
} 
For example, starting with a society of always-single low-educated individuals and introducing marriage and divorce according to the empirical probabilities reduces the optimal single-program generosity of Social Assistance from $80 \%$ to $66 \%$ of the baseline level, a reduction of $17.5 \%$. Introducing marriage and divorce reduces the optimal single-program generosity of Social Assistance by $12 \%$ for high-educated individuals. The increasing importance of marriage to the optimal generosity of Social Assistance as education decreases reflects that the intra-household insurance offered by marriage has relatively high value to low-educated individuals, who have low wages and high employment risk. For the most relevant case of a society containing the empirical frequencies of high-educated and low-educated individuals, introducing marriage and divorce reduces the optimal singleprogram generosity of Social Assistance from $72 \%$ to $59 \%$ of the baseline level, a reduction of $18 \%$. The change in the optimal generosity of Social Assistance that arises when high-educated and low-educated individuals who marry and divorce are combined into one society reflects redistributive concerns and changing marriage patterns, as individuals start to marry between as well as within education groups. The change in marriage patterns affects risk exposure and intra-household insurance options, and mediates the redistributive motive. Meanwhile, given the baseline Social Assistance system, the optimal single-program Unemployment Insurance replacement rate remains at $0 \%$ following the introduction of marriage and divorce according to the empirical probabilities.

With the introduction of marriage, the optimal mix continues to be assistance-orientated, and is characterized by moderately generous Social Assistance and, depending on the distribution of education, either low or zero Unemployment Insurance benefits. Specifically, within education groups the optimal mix features Unemployment Insurance benefits with a replacement rate of $10 \%$. The insurance incentive-trade-off therefore favors the provision of a small amount of insurance against employment shocks to individuals with a working spouse, which cannot be provided by household-level Social Assistance benefits. Redistributive concerns, partly mediated by changes in marriage patterns, arise for a society of high-educated and low-educated single and married individuals. Consequently, combining high-educated and low-educated individuals into one society decreases the optimal replacement rate from 10\% to 0\%: Unemployment Insurance is no longer part of the optimal mix, and households rely solely on the more redistributive Social Assistance.

As for the single-program generosity of Social Assistance, introducing marriage and divorce reduces the optimal generosity of Social Assistance in the optimal mix, with the effect of marriage being larger for low-educated individuals than for high-educated individuals. Quantitatively, moving from a society of always-single individuals to a society in which individuals marry and divorce according to the empirical probabilities reduces the optimal generosity of Social Assistance benefits in the optimal mix by $16-22 \%$, depending on education. In summary, the family context is an important determinant of the optimal generosity of Social Assistance benefits, both when the Unemployment Insurance system 
maintains the baseline replacement rate of $60 \%$ and when the generosities of Social Assistance and Unemployment Insurance are considered jointly. In contrast, the optimal Unemployment Insurance replacement rate is zero or close to zero, irrespective of the distribution of education and marital status in the population, and irrespective of whether we focus the design of Unemployment Insurance in isolation or consider the optimal mix of Social Assistance and Unemployment Insurance benefits.

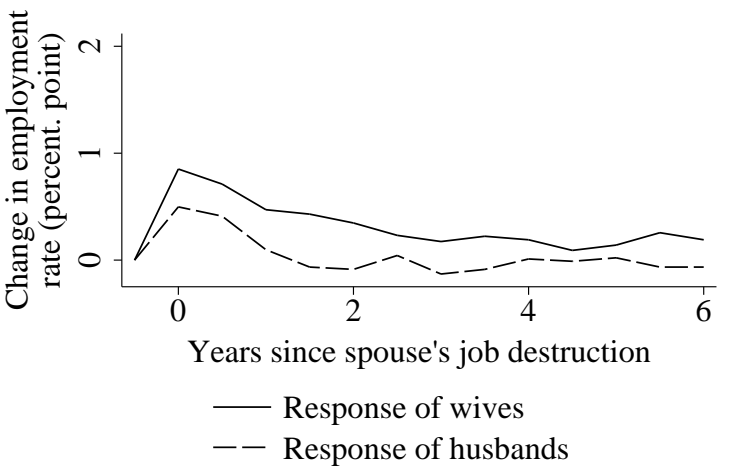

(a) With estimated leisure complementarities.

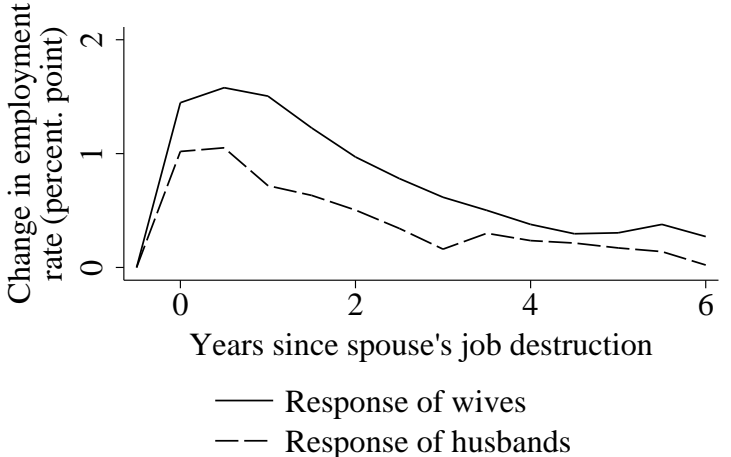

(b) Without leisure complementarities.

Notes: The cross-spouse labor supply response is obtained by considering in turn the age points 20, 30 and 40 years, and using the estimated model to simulate optimal household behavior when one spouse is not subject to a job destruction at the age point of interest and when the same spouse is subject to an unanticipated job destruction at the age point of interest. The figures illustrate the spousal response, averaged over the three age points. Employment is defined as either full-time or part-time work. We consider optimal household behavior in each scenario, and therefore the spouse subject to a job destruction may subsequently return to employment. Results refer to households that remained married between 6 months before and 6 years after the age point of interest.

Figure 6: Average employment response to spouse's job loss with and without complementarities between the husband's and wife's leisure times.

As explained in Section 6.1, dependence of the optimal generosity of Social Assistance on the family context reported in Table 6 arises from heterogeneity by family type in the insurance, incentive and redistributive effects of social programs, in the pooling of risks within the household and in the availability of intra-household insurance from shared savings and family labor supply. Here, we explore the cross-spouse labor supply response to job destruction, and we thus make a link between the family labor supply process and the welfare effects of program reforms. Figure 6(a) illustrates how the labor supply of wives and husbands responds to their partners' job destructions when individuals enjoy the estimated degree of complementarity between the spouses' leisure times. These results were obtained by simulating couples' behavior from the estimated model and thus account for the effect of job destructions on both spouses' labor supply behavior. The cross-spouse 
employment response appears to be important in mitigating the effects of job destruction. Both husbands and wives increase employment contemporaneously in response to their spouses' job destructions: the employment rate of husbands increases by 0.50 percentage points in immediate response to their wives' job destructions, while the employment rate of wives increases by 0.85 percentage points in the period of their husbands' job destructions. ${ }^{39}$ Further, the spousal employment response is persistent, particularly among women; for example, the husband's job destruction increases the probability of the wife being in employment 6 years later by 0.19 percentage points.

Figure 6(b) shows that removing between-spouse leisure complementarities increases the immediate cross-spouse labor supply response to job destruction and increases the persistence of the cross-spouse response: on average, shutting down between-spouse leisure complementarities increases the employment response of wives to their husbands' job destructions by a factor of 2.24 and increases the response of husbands to their wives' job destructions by a factor of 1.87. These findings reflect that between-spouse leisure complementarities moderate the cross-spouse labor supply response by providing a utility benefit to joint non-work. ${ }^{40}$ The change in the cross-spouse labor supply response to job loss that arises from the removal of leisure complementarities suggests that the preference for joint non-work is itself an important input to the optimal design of social programs.

\section{Conclusion}

By building and estimating a dynamic life-cycle model that links directly household behavior, social insurance and assistance programs and intra-household insurance instruments, including family labor supply, we have explored the effective design of social insurance and assistance programs for a population of singles and married couples. Furthermore, we have provided insights into the importance of the family unit for the optimal design of social programs. Our framework recognizes that the insurance, incentive and redistributive effects social insurance and assistance programs vary between singles and married couples, and incorporates intra-household insurance instruments that vary between singles and married couples. Among other family unit-based differences, our analysis recognizes that married couples may obtain insurance by adjusting either one spouse's or both spouses' labor supply in response to wage and employment shocks. Meanwhile, single-adult households have just one source of potential labor earnings and, therefore, are more limited in

\footnotetext{
${ }^{39}$ According to the timing of events in the model, shown in Figure 1, the household members observe job destructions for both spouses prior to making search and labor supply decisions. It is therefore possible for the couple to increase one spouse's labor supply contemporaneously in response to the other spouse's job destruction.

${ }^{40}$ For empirical evidence on the relevance of leisure complementarities to hours of work, see e.g., Goux et al. (2014).
} 
their ability to use labor supply to mitigate the impact of shocks.

Our empirical results shed light on the effective design of the composite social insurance and assistance system. We find that assistance-orientated systems dominate insurance-orientated systems. In the preferred social insurance and assistance system, permanent universal Social Assistance benefits provide income of last-resort to low-income households, and there is little or no role for temporary earnings-related Unemployment Insurance benefits. We also find that the presence of married couples in the population markedly decreases the optimal generosity of the Social Assistance system. This result reflects that married couples optimally draw on intra-household insurance from family labor supply and increase one spouse's labor supply in response to the other spouse's job loss.

Our analysis provides several further insights. We show that the use of family labor supply as an intra-household insurance device depends on the strength of within-household between-spouse leisure complementarities, which reward coordination on joint non-work. Understanding the policy relevance of intra-household insurance, and in particular interpreting any added worker effects, therefore requires recognition of the preference-based drivers of couples' behavior. Finally, our results highlight interdependencies between social assistance programs targeted at low-income populations, such as programs that guarantee a household income floor, and social insurance programs that provide earningsrelated benefits, such as Unemployment Insurance. In our setting, we found only minimal justification for temporary earnings-related benefits, provided that social assistance programs protect households against highly unfavorable events. 


\section{Appendix}

\section{A Marriage, Divorce, Spousal Education, Fertility and Job Destructions}

This appendix describes the exogenous processes that determine marital status, spousal education, fertility outcomes and job destructions. We also describe how the parameters of these processes are estimated prior to estimation of the life-cycle model.

\section{A.1 Marriage and Divorce}

Marriage occurs with a probability that depends on the individual's gender, age and education, and a married couple divorces with a probability that depends on the age and education of the female spouse. Further, women may marry only prior to age 65 years, while men may marry only prior to age 62.5 years. Divorce may occur only prior to the wife reaching age 62.5 years.

Marriage probabilities are estimated using a Lowess regressions of marriage on age, using a sample of individuals who were single in the previous period. Similarly, divorce probabilities are estimated using Lowess regressions of divorce on the age of the female spouse, using a sample of women who were married in the previous period. Figure 7 illustrates the estimated semi-annual marriage and divorce probabilities.
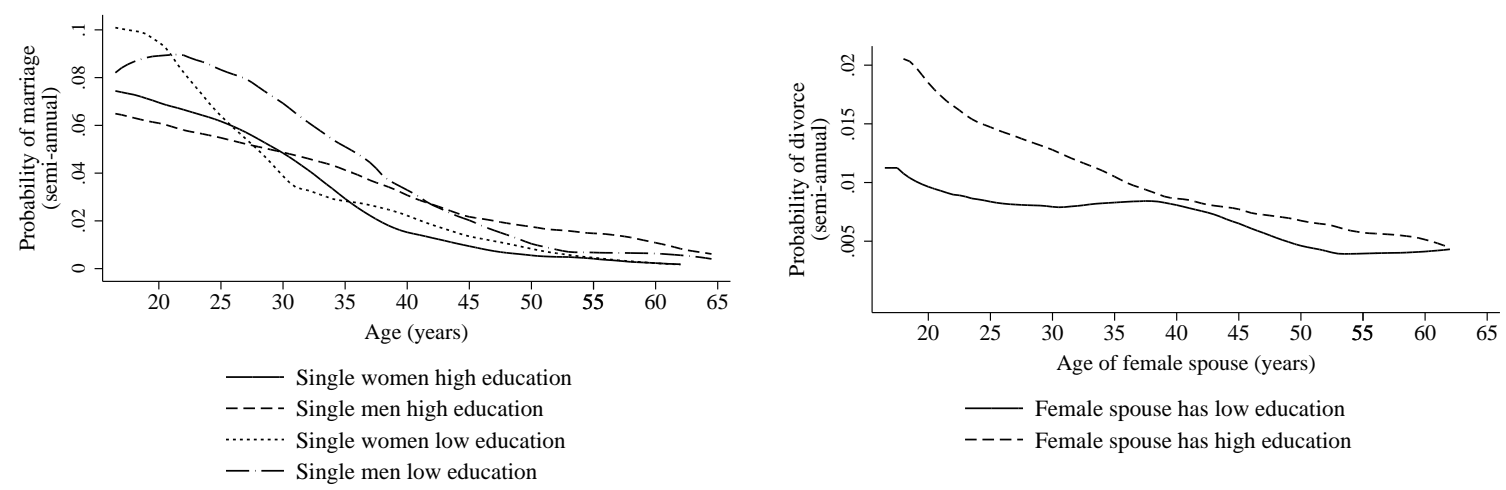

Notes: Estimation uses the SOEP sample for 1991-2005 (see Table 1). High education is defined as 12 or more years of education.

Figure 7: Semi-annual marriage and divorce probabilities. 


\section{A.2 Spousal Education}

The years of education of a new spouse married to individual $g$ (SpouseEduc $g$ ) is assumed to follow a censored normal distribution. Let Male indicate $g$ 's gender and let Education $_{g}$ denote $g$ 's years of education. Then:

$$
\text { SpouseEduc }_{g}=\min \left\{\max \left\{\operatorname{SpouseEduc}_{g}^{*}, 10\right\}, 19\right\} \text { for } g=i, j \text {, }
$$

where:

SpouseEduc $_{g}^{*} \sim N\left(\lambda_{1}+\lambda_{2}\right.$ Male $_{g}+\lambda_{3}$ Education $_{g} \times$ Male $_{g}+\lambda_{4}$ Education $_{g} \times\left(1-\right.$ Male $\left.\left._{g}\right), \sigma_{S}^{2}\right)$.

We estimate the parameters of the above equation using a sample of 1532 newly-formed married couples and obtain (standard errors in parentheses): $\lambda_{1}=7.860(0.541) ; \lambda_{2}=$ $1.991(1.001) ; \lambda_{3}=0.520(0.036) ; \lambda_{4}=0.640(0.037) ;$ and $\sigma_{S}^{2}=2.332(0.048)$.

\section{A.3 Fertility}

The first child arrives with a probability that depends on the woman's age, education and marital status. The probability of birth of the first child is assumed to be zero for women aged below 18 years or 38 years and older. For women aged 18-37.5 years, the probability of birth of the first child is estimated using Lowess regressions of a first birth indicator on age. Figure 8 illustrates the estimated semi-annual probabilities of the birth of the first child.

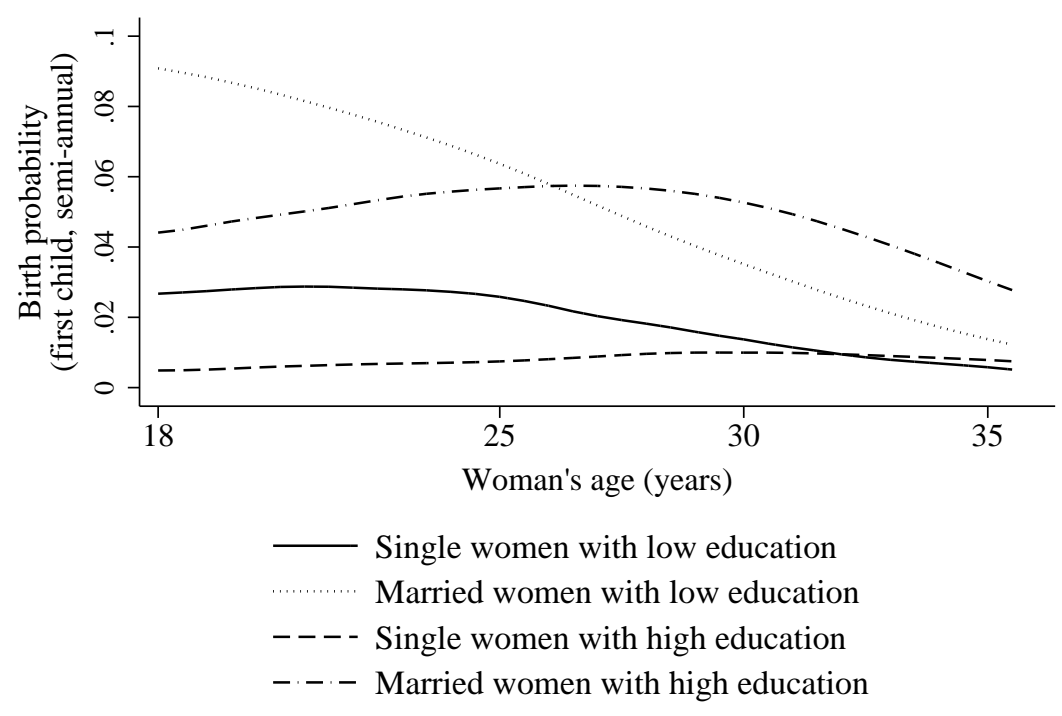

Notes: Estimation uses the SOEP sample for 1991-2005 (see Table 1). The sample is further restricted to women aged 18-37.5 without preexisting children. High education is defined as 12 or more years of education.

Figure 8: Semi-annual birth probabilities. 
A second child is assumed to arrive three years after the first child, and no further children are born. Children reside in the mother's household until they reach age 18 years, at which point they leave the household. The age of the first-born child summarizes fully the number and age of a woman's children, and therefore the age of the first-born child is the only child-related variable included in the state space.

\section{A.4 Job Destructions}

We estimate the job destruction probabilities using information in the annual SOEP surveys on the reasons that newly non-employed individuals left previous employment. Using this information, we identify involuntary separations, defined as separations attributed to layoff, plant closure or the termination of a temporary contract. We estimate the probability of an involuntary separation conditional on a transition out of employment. We also estimate the semi-annual probability of a transition out of employment. Both probabilities are allowed to vary according to the individual's gender, age, education and marital status. Table 7 reports the estimated job destruction probabilities, obtained by taking the product of the probability of an involuntary separation, conditional on a transition out of employment, and the semi-annual probability of a transition out of employment.

\begin{tabular}{|c|c|c|}
\hline & \multicolumn{2}{|c|}{ Single individuals } \\
\hline & Women & Men \\
\hline High education and age $\geq 50$ years & 0.041 & 0.032 \\
\hline High education and age $<50$ years & 0.017 & 0.018 \\
\hline Low education and age $\geq 50$ years & 0.024 & 0.042 \\
\hline \multirow[t]{3}{*}{ Low education and age $<50$ years } & 0.024 & 0.020 \\
\hline & \multicolumn{2}{|c|}{ Married individuals } \\
\hline & Women & Men \\
\hline High education and age $\geq 50$ years & 0.029 & 0.014 \\
\hline High education and age $<50$ years & 0.019 & 0.006 \\
\hline Low education and age $\geq 50$ years & 0.039 & 0.029 \\
\hline Low education and age $<50$ years & 0.020 & 0.020 \\
\hline
\end{tabular}

Notes: Estimation uses the SOEP sample for 1991-2005 (see Table 1).

High education refers to 12 or more years of education.

Table 7: Semi-annual job destruction probabilities. 


\section{B Social Security Contributions, Income tax, Pen- sions, Child benefits, and Child-care Costs}

This appendix describes our modeling of Social Security Contributions, income tax, pensions, child benefits and child-care costs. The specification is based on the German system. Social Assistance and Unemployment Insurance benefits are described above in Sections 2.6.2 and 2.6.3.

Individuals pay Social Security Contributions (SSC) for health, unemployment and public pension benefits. SSC amount to about $20 \%$ of gross earned income below a cap of around 4,300 Euros per month. Employers are required to match employees' contributions. ${ }^{41}$ In contrast to SSC, income tax is computed at the household level: for a single household income tax is based on the individual's taxable income, while for a couple household income is taxed jointly and the tax is based on the average of the spouses' taxable incomes. Taxable income comprises gross income from employment above an exemption threshold and gross interest income above a disregard, less SSC. The income tax function is a smooth progressive function of average household taxable income above an exemption threshold. Conditional on average household taxable income, a couple household's income tax liability is twice that of a single household. Households pay a further tax (Solidaritaetszuschlag) of $5.5 \%$ of the household income tax liability.

Under the German pension system, individuals accumulate pension entitlement for each year of work, with the entitlement being roughly proportional to annual earnings (for further details see Börsch-Supan and Wilke, 2004, and Haan and Prowse, 2014). Mirroring this, in our model a retired individual receives an annual pension that is proportional to his or her approximate life-time earnings:

$$
\text { Pension }_{g, t}=\Xi \times \operatorname{Exp}_{g, t} \times W_{g}\left(\text { Education }_{g}, 0.5 \times \operatorname{Exp}_{g, t}, \bar{\kappa}\right) \text { for } g=i, j .
$$

In the above, Exp continues to denote years of experience, and the function $W_{g}()$ denotes the gender-specific market wage function (4) evaluated at the individual's education, average experience over the life-cycle, and the population average of the wage unobservable, $\bar{\kappa} \cdot{ }^{42}$ Reflecting the pension system that was effective during the sample period, we set the proportionality factor $\Xi$ to 20 . Retirement is mandatory at age 65 years, and is feasible from age 60 for women and from age 63 for men.

The model includes child benefits worth 150 Euros per month for each dependent child. Social Assistance benefits, which include a child-related component, are withdrawn at a rate of $100 \%$ against child benefits, however child benefits do not affect Unemployment

\footnotetext{
${ }^{41} \mathrm{We}$ account for individual and employer Social Security Contributions when calculating revenue equivalent policy reforms (Section 6 and footnote 34 ).

${ }^{42}$ The population average of the wage unobservable, $\bar{\kappa}$, is computed using the steady state distribution. See footnote 12.
} 
Insurance benefits. We also model child-care costs. We assume that a married couple with one or more pre-school aged children must pay for full-time child-care if both spouses work full-time. Part-time child-care costs are incurred if the wife works part-time and the husband works full-time. Similarly, a single woman with one or more pre-school aged children must pay child-care costs reflecting her hours of work. Based on Wrohlich (2011), we estimate expected monthly child-care costs for a child younger than 3 years of 183 Euros for part-time care and 397 Euros for full-time care. The corresponding figures for a child aged between 3 and 6 years are 90 Euros and 167 Euros. These figures reflect the relatively limited access to subsidized child-care for infants, and assume a price of 5 Euros per hour for unsubsidized child-care.

\section{Social Assistance Income Floor}

The Social Assistance income floor depends on marital status and on the number and ages of any children present in the household. We represent the Social Assistance income floor by the product of a baseline generosity, $G$, and a household equivalence scale, $E$ :

$$
\text { SAFloor }=G \times E(\text { Married, AgeFirstChild }) \text {, }
$$

where Married is an indicator for the household being a married couple, and AgeFirstChild is the age of the woman's first-born child (as discussed in Appendix A.3, this variable summarizes fully the number and age of a woman's children). The household equivalence scale is normalized to one for a single household without children, and is incremented for the presence of additional adults and children. Specifically:

$$
\begin{aligned}
E(\text { Married, AgeFirstChild })= & 1+0.73 \text { Married }+0.5(\# \mathrm{Ch} 0-6)+0.65(\# \mathrm{Ch} 7-13)+ \\
& 0.9(\# \mathrm{Ch} 14-17)+0.05(\# \mathrm{Ch} 0-6) \times(1-\text { Married })+ \\
& 0.4 \times \mathbf{1}(\text { AnyCh0 }-17) \times(1-\text { Married })
\end{aligned}
$$

In the above, the terms (\#ChX-Y) refer to the number of children aged between $\mathrm{X}$ and $\mathrm{Y}$ years inclusive, and $\mathbf{1}(\mathrm{AnyCh} 0-17)$ is an indicator for the presence of any child age 17 years or younger in the household. The baseline generosity, $G$, is 600 Euros per month.

\section{Auxiliary Model Parameters}

Tables 8 and 9 describe the auxiliary model parameters and link the specification of the auxiliary model to identification of the parameters of the life-cycle model described in Section 2 . 


\begin{abstract}
Auxiliary model parameters
Group 1: Mean log wage for: all women; women with high education; women with high experience; women whose youngest child is aged under 3 years; women whose youngest child is aged 3 or over and under 6 years; women whose husband has high education.
\end{abstract}

Number Structural parameters primarily identified, and notes

6 Intercept and coefficients on education and experience in the wage process for women $\left(\beta_{1}^{F}, \beta_{2}^{F}, \beta_{3}^{F}\right)$.

Note: the inclusion of information on wages specifically for women with children and with a high educated husband ensures the separation of selection effects from determinants of the market wage.

Group 2: Parameters in Group 1. estimated for $6 \quad \beta_{1}^{M}, \beta_{2}^{M}, \beta_{3}^{M}$.
men.

Group 3: Variance of log wage for women and for men.

$2 \quad$ Standard deviation of wage measurement error for women and men $\left(\sigma_{\nu F}, \sigma_{\nu M}\right)$.

Group 4: Correlation of spouses' contemporaneous $1 \quad$ Between-spouse correlation of perlog wages. $\quad$ sistent wage shocks $(\varrho)$.

Group 5: Covariance between log wage at $t$ and $t-2 \quad 2 \quad$ Loadings on persistent unobservfor women and for men. able in the wage processes for women and men $\left(\beta_{4}^{F}, \beta_{4}^{M}\right)$.

Group 6: Log odds ratio of the probability that a woman who was employed at $t-2$ with a log wage less than 2.5 experiences a wage increase between periods $t-2$ and $t$; log odds ratio of the probability that a woman who was employed at $t-2$ with a log wage greater than 2.5 experiences a wage decrease between periods $t-2$ and $t$.

\begin{tabular}{|c|c|c|}
\hline$\frac{\text { Group 7: Parameters in Group 6. estimated for }}{\text { men. }}$ & 2 & $\theta_{0}^{M}, \theta_{1}^{M}$ \\
\hline $\begin{array}{l}\text { Group 8: Log odds ratios of the probabilities of a } \\
\text { voluntary quit at time } t \text { and of full-time employ- } \\
\text { ment at time } t \text {, given employed at time } t-1 \text { for: } \\
\text { single and married women aged under } 50 \text {; and sin- } \\
\text { gle and married women aged } 50-65 \text {. Log odds ra- } \\
\text { tios of probabilities of full-time and part-time em- } \\
\text { ployment for single and married women: whose } \\
\text { youngest child is aged under } 3 \text { years; and whose } \\
\text { youngest child is aged } 3 \text { or over and under } 6 \text { years. }\end{array}$ & 16 & $\begin{array}{l}\text { Preference of women for } \\
\text { consumption when work- } \\
\text { ing full-time or part-time } \\
\left(\eta_{1, F T}^{F}, \eta_{2, F T}^{F}, \eta_{1, P T}^{F}, \eta_{2, P T}^{F}\right) \text {. } \\
\text { Note: With the exception of age } \\
\text { effects, the employment-state spe- } \\
\text { cific consumption preference of } \\
\text { married individuals is identified } \\
\text { from information on singles. }\end{array}$ \\
\hline
\end{tabular}

Notes: High experience is defined as 20 or more years of experience. We take the following steps to ensure that the same wage selection rules apply to the simulated sample and to the estimation sample: the simulated wage observations include measurement error; simulated wage observations are included only for employed individuals and only in the first half of each year (in the estimation sample, the wage is only observed at the time of annual interview, which typically falls between January and June); and simulated wage observations are excluded with the non-response probability observed in the estimation sample.

Table 8: Auxiliary model parameters I. 


\begin{tabular}{|c|c|c|}
\hline Auxiliary model parameters & Number & $\begin{array}{l}\text { Structural parameters primarily } \\
\text { identified, and notes }\end{array}$ \\
\hline $\begin{array}{l}\text { Group 9: Log odds ratio of the probability of a vol- } \\
\text { untary quit at time } t \text { given employed at time } t-1 \\
\text { for: single and married men aged under } 50 \text {; single } \\
\text { and married men aged 50-65. }\end{array}$ & 4 & $\begin{array}{l}\text { Preference of men for consump- } \\
\text { tion when working full-time. } \\
\left(\eta_{1, F T}^{M}, \eta_{2, F T}^{M}\right) \text {. }\end{array}$ \\
\hline $\begin{array}{l}\text { Group 10: Log odds ratios of the probabilities of } \\
\text { full-time employment and part-time employment for: } \\
\text { single women with high education and low experi- } \\
\text { ence; single women with high education and high }\end{array}$ & 20 & $\begin{array}{l}\text { Parameters of the job of- } \\
\text { fer probability for women } \\
\left(\chi_{1}^{F}, \chi_{2}^{F}, \chi_{3}^{F}, \chi_{4}^{F}\right) \text {. }\end{array}$ \\
\hline $\begin{array}{l}\text { experience; single women with high education and } \\
\text { low experience; single women with low education and } \\
\text { high experience; single women aged under } 50 \text {; and } \\
\text { single women aged 50-65. Same log odds ratios for } \\
\text { married women. }\end{array}$ & & $\begin{array}{l}\text { Note: Given the employment- } \\
\text { state specific preference for con- } \\
\text { sumption, employment levels are } \\
\text { informative about the job offer } \\
\text { probability, which impacts the } \\
\text { transition rate into employment. }\end{array}$ \\
\hline $\begin{array}{l}\text { Group 11: Log odds ratio of the probability of full- } \\
\text { time employment for: single men with high educa- }\end{array}$ & 10 & $\begin{array}{l}\text { Parameters of the job of- } \\
\text { fer probability for men } \\
\left(\chi_{1}^{M}, \chi_{2}^{M}, \chi_{3}^{M}, \chi_{4}^{M}\right) \text {. }\end{array}$ \\
\hline
\end{tabular}
ucation and high experience; single men with high education and low experience; single men with low education and high experience; single men aged under 50; and single men aged 50-65. Same log odds ratios for married men.

\begin{tabular}{|c|c|c|}
\hline $\begin{array}{l}\text { Group 12: Log odds ratios of the probability of hus- } \\
\text { band non-employed and: wife working full-time; wife } \\
\text { working part-time; and wife non-employed. Log odds } \\
\text { ratios of the probability of husband non-employed } \\
\text { and: wife working part-time; and wife non-employed. }\end{array}$ & 5 & $\begin{array}{l}\text { Between-spouse leisure comple- } \\
\text { mentarity parameter }\left(\eta_{3}\right) \text { and } \\
\text { weight on woman's utility in cou- } \\
\text { ples' objective function }(\alpha) \text {. }\end{array}$ \\
\hline $\begin{array}{l}\text { Group 13: Mean household wealth for: single women } \\
\text { aged less than 50; single women aged } 50 \text { and above; } \\
\text { single women with high education; single men aged } \\
\text { less than 50; single men aged } 50 \text { or above; single men } \\
\text { with high education; married households where hus- } \\
\text { band is aged under 50; married households where } \\
\text { husband is aged } 50 \text { or above; married households } \\
\text { where husband has high education. }\end{array}$ & 9 & $\begin{array}{l}\text { Coefficients of relative risk } \\
\text { aversion for women and men } \\
\left(\rho^{F}, \rho^{M}\right) \text {. }\end{array}$ \\
\hline $\begin{array}{l}\text { Group 14: Log odds ratio of the probability of vol- } \\
\text { untary quit at time } t \text { given full-time employment at }\end{array}$ & 24 & $\begin{array}{l}\text { Standard deviation of preference } \\
\text { shocks }\left(\sigma_{F S}, \sigma_{F C}, \sigma_{M S}, \sigma_{M C}\right)\end{array}$ \\
\hline
\end{tabular}
time $t-1$ for single and married men and women with: high experience and high education; high experience and low education; low experience and high education. Log odds ratio of the probability of voluntary quit at time $t$ given employed at time $t-1$ and $t-2$ for single and married men and women. Log odds ratio of the probability of full-time employment at time $t$ given employed at time $t-1$ and $t-2$ for single and married women.

Note: Conditional on income, preferences do not depend on experience or education. Variation in behavior along these dimensions therefore provides identifying information about the scale of preference unobservables.

Notes: See notes to Table 8.

Table 9: Auxiliary model parameters II. 


\section{E Internal Goodness of Fit}

\begin{tabular}{|c|c|c|c|c|}
\hline \multirow{2}{*}{ Mean of: } & \multicolumn{2}{|c|}{ Single women } & \multicolumn{2}{|c|}{ Married women } \\
\hline & Observed & Simulated & Observed & Simulated \\
\hline Full-time work | Age $<50$ & 0.54 & 0.54 & 0.29 & 0.30 \\
\hline Part-time work $\mid$ Age $<50$ & 0.16 & 0.16 & 0.30 & 0.30 \\
\hline Full-time work $\mid$ Age $\geq 50$ & 0.44 & 0.44 & 0.22 & 0.24 \\
\hline Part-time work $\mid$ Age $\geq 50$ & 0.12 & 0.12 & 0.26 & 0.28 \\
\hline Full-time work | High Educ. \& High Exp. & 0.70 & 0.65 & 0.43 & 0.35 \\
\hline Part-time work | High Educ. \& High Exp. & 0.12 & 0.15 & 0.33 & 0.33 \\
\hline Full-time work $\mid$ Low Educ. \& High Exp. & 0.49 & 0.52 & 0.35 & 0.33 \\
\hline Part-time work | Low Educ. \& High Exp. & 0.15 & 0.14 & 0.33 & 0.31 \\
\hline Full-time work $\mid$ High Educ. \& Low Exp. & 0.57 & 0.56 & 0.28 & 0.28 \\
\hline Part-time work | High Educ. \& Low Exp. & 0.18 & 0.18 & 0.31 & 0.30 \\
\hline Voluntary quit $\mid$ Age $<50$ \& Emp. at $t-1$ & 0.02 & 0.02 & 0.03 & 0.03 \\
\hline Voluntary quit | Age $\geq 50$ \& Emp. at $t-1$ & 0.04 & 0.04 & 0.03 & 0.03 \\
\hline Voluntary quit | High Educ. \& High Exp. \& Emp. at $t-1$ & 0.02 & 0.02 & 0.03 & 0.03 \\
\hline Voluntary quit | Low Educ. \& High Exp. \& Emp. at $t-1$ & 0.02 & 0.02 & 0.02 & 0.02 \\
\hline Voluntary quit | High Educ. \& Low Exp. \& Emp. at $t-1$ & 0.03 & 0.03 & 0.02 & 0.02 \\
\hline Voluntary quit | Emp. at $t-2 \&$ Emp. at $t-1$ & 0.03 & 0.02 & 0.04 & 0.04 \\
\hline Full-time work $\mid$ Age $<50$ \& Emp. at $t-1$ & 0.75 & 0.73 & 0.48 & 0.48 \\
\hline Full-time work $\mid$ Age $\geq 50$ \& Emp. at $t-1$ & 0.76 & 0.75 & 0.44 & 0.44 \\
\hline Full-time work $\mid$ High Educ. \& High Exp. \& Emp. at $t-1$ & 0.77 & 0.74 & 0.47 & 0.47 \\
\hline Full-time work $\mid$ Low Educ. \& High Exp. \& Emp. at $t-1$ & 0.83 & 0.78 & 0.55 & 0.48 \\
\hline Full-time work $\mid$ High Educ. \& Low Exp. \& Emp. at $t-1$ & 0.74 & 0.74 & 0.50 & 0.49 \\
\hline Full-time work $\mid$ Emp. at $t-2 \&$ Emp. at $t-1$ & 0.74 & 0.73 & 0.44 & 0.45 \\
\hline Full-time work $\mid$ Age $<50$ \& Youngest child aged $<3$ & 0.16 & 0.09 & 0.10 & 0.11 \\
\hline Part-time work $\mid$ Age $<50 \&$ Youngest child aged $<3$ & 0.34 & 0.29 & 0.32 & 0.33 \\
\hline Full-time work $\mid$ Age $<50 \& 3 \leq$ Youngest child aged $<6$ & 0.29 & 0.21 & 0.15 & 0.17 \\
\hline Part-time work $\mid$ Age $<50 \& 3 \leq$ Youngest child aged $<6$ & 0.42 & 0.45 & 0.41 & 0.42 \\
\hline
\end{tabular}

Notes: Emp. refers to full-time and part-time employment combined. High Exp. is 20 or more years of experience. High Educ. is 12 or more years of education.

Table 10: Internal goodness of fit I: Labor supply of single and married women. 


\begin{tabular}{|c|c|c|c|c|}
\hline \multirow{2}{*}{ Mean of: } & \multicolumn{2}{|c|}{ Single men } & \multicolumn{2}{|c|}{ Married men } \\
\hline & Observed & Simulated & Observed & Simulated \\
\hline \begin{tabular}{l|l} 
Full-time work $\mid$ Age $<50$
\end{tabular} & 0.76 & 0.75 & 0.82 & 0.83 \\
\hline Full-time work $\mid$ Age $\geq 50$ & 0.59 & 0.54 & 0.61 & 0.63 \\
\hline Full-time work | High Educ. \& High Exp. & 0.76 & 0.63 & 0.79 & 0.81 \\
\hline Full-time work $\mid$ Low Educ. \& High Exp. & 0.64 & 0.66 & 0.70 & 0.71 \\
\hline Full-time work $\mid$ High Educ. \& Low Exp. & 0.81 & 0.83 & 0.92 & 0.91 \\
\hline Voluntary quit $\mid$ Age $<50 \&$ Emp. at $t-1$ & 0.02 & 0.02 & 0.01 & 0.01 \\
\hline Voluntary quit $\mid$ Age $\geq 50$ \& Emp. at $t-1$ & 0.04 & 0.03 & 0.03 & 0.03 \\
\hline Voluntary quit $\mid$ High Educ. \& High Exp. \& Emp. at $t-1$ & 0.02 & 0.02 & 0.01 & 0.02 \\
\hline Voluntary quit | Low Educ. \& High Exp. \& Emp. at $t-1$ & 0.02 & 0.03 & 0.02 & 0.02 \\
\hline Voluntary quit $\mid$ High Educ. \& Low Exp. \& Emp. at $t-1$ & 0.02 & 0.02 & 0.02 & 0.03 \\
\hline Voluntary quit $\mid$ Emp. at $t-2 \&$ Emp. at $t-1$ & 0.02 & 0.02 & 0.01 & 0.01 \\
\hline
\end{tabular}

Notes: See notes to Table 10.

Table 11: Internal goodness of fit II: Labor supply of single and married men.

\begin{tabular}{|c|c|c|}
\hline Mean of: & Observed & Simulated \\
\hline Wealth | Single man age $<50$ & 0.26 & 0.35 \\
\hline Wealth | Single men age $\geq 50$ & 0.75 & 0.94 \\
\hline Wealth $\mid$ Single men with High Educ. & 0.48 & 0.51 \\
\hline Wealth $\mid$ Single woman age $<50$ & 0.35 & 0.45 \\
\hline Wealth $\mid$ Single women age $\geq 50$ & 0.86 & 0.82 \\
\hline Wealth | Single women with High Educ. & 0.51 & 0.65 \\
\hline Wealth | Married household with husband age $<50$ & 1.11 & 1.07 \\
\hline Wealth | Married household with husband age $\geq 50$ & 1.97 & 1.92 \\
\hline Wealth | Married household with husband High Educ. & 1.68 & 1.55 \\
\hline Wife non-employed and Husband non-employed & 0.04 & 0.04 \\
\hline Wife part-time work and Husband non-employed & 0.02 & 0.02 \\
\hline Wife full-time work and Husband non-employed & 0.04 & 0.03 \\
\hline Wife non-employed and Husband full-time work & 0.33 & 0.33 \\
\hline Wife part-time work and Husband full-time work & 0.29 & 0.29 \\
\hline
\end{tabular}

Notes: Joint labor supply outcomes are summarized for married households in which at least one spouse is aged under 50. Wealth is measured in 1000s of Euros. Also see notes to Table 10.

Table 12: Internal goodness of fit III: Joint labor supply outcomes in married households, and wealth by household type. 


\begin{tabular}{|c|c|c|}
\hline Quantity & Observed & Simulated \\
\hline Mean wage | Woman & 2.42 & 2.43 \\
\hline Mean wage | Woman \& High educ. & 2.51 & 2.51 \\
\hline Mean wage | Woman \& High exp. & 2.51 & 2.49 \\
\hline Mean wage | Woman \& Spouse High educ. & 2.46 & 2.43 \\
\hline Mean wage $\mid$ Woman \& Youngest child aged $<3$ & 2.39 & 2.45 \\
\hline Mean wage $\mid$ Woman $\& 3 \leq$ Youngest child aged $<6$ & 2.36 & 2.43 \\
\hline Mean wage | Man & 2.75 & 2.76 \\
\hline Mean wage $\mid$ Man \& High educ. & 2.85 & 2.86 \\
\hline Mean wage $\mid$ Man \& High exp. & 2.77 & 2.80 \\
\hline Mean wage | Man \& Spouse high educ. & 2.85 & 2.80 \\
\hline Mean wage $\mid$ Man \& Youngest child aged $<3$ & 2.75 & 2.75 \\
\hline Mean wage $\mid$ Man $\& 3 \leq$ Youngest child aged $<6$ & 2.79 & 2.74 \\
\hline Wage variance | Woman & 0.15 & 0.14 \\
\hline Wage variance $\mid$ Man & 0.15 & 0.15 \\
\hline Covariance of husband's and wife's wages & 0.04 & 0.04 \\
\hline Mean absolute wage change between $t-2$ and $t \mid$ Woman and previous wage $<2.5$ & 0.41 & 0.42 \\
\hline Mean absolute wage change between $t-2$ and $t \mid$ Woman and previous wage $\geq 2.5$ & 0.49 & 0.49 \\
\hline Mean absolute wage change between $t-2$ and $t \mid$ Man and previous wage $<2.5$ & 0.33 & 0.38 \\
\hline Mean absolute wage change between $t-2$ and $t \mid$ Man and previous wage $\geq 2.5$ & 0.51 & 0.51 \\
\hline Intertemporal wage correlation | Woman & 0.11 & 0.13 \\
\hline Intertemporal wage correlation | Man & 0.12 & 0.12 \\
\hline
\end{tabular}

Notes: Wages are in logs. All quantities are computed from observations on employed individuals. In the estimation sample, the wage exclusions (child variables and spouse's education) are jointly significant (p. value $<0.01$ for women and for men). The notes to Table 8 provide further details on the treatment of wages in the estimation procedure.

Table 13: Internal goodness of fit IV: Wages. 


\section{References}

Acemoglu, D. and Shimer, R. (1999). Efficient Unemployment Insurance. Journal of Political Economy, 107(5): 893-928

Adda, J., Dustmann, C., and Stevens, K. (2011). The Career Costs of Children. CEPR Discussion Paper Number 8697

Altonji, J.G., Smith, A.A., and Vidangos, I. (2013). Modeling Earnings Dynamics. Econometrica, 81(4): 1395-1454

Atkinson, A.B. and Micklewright, J. (1991). Unemployment Compensation and Labor Market Transitions: A Critical Review. Journal of Economic Literature, 29(4): 1679-1727

Attanasio, O., Low, H., and Sanchez-Marcos, V. (2008). Explaining Changes in Female Labor Supply in a Life-cycle Model. American Economic Review, 98(4): 15171552

Attanasio, O.P. and Weber, G. (1995). Is Consumption Growth Consistent with Intertemporal Optimization? Evidence from the Consumer Expenditure Survey. Journal of Political Economy, 103(6): 1121-1157

Baily, M.N. (1978). Some Aspects of Optimal Unemployment Insurance. Journal of Public Economics, 10(3): 379-402

Blau, D.M. and Gilleskie, D.B. (2006). Health Insurance and Retirement of Married Couples. Journal of Applied Econometrics, 21(7): 935-953

Blundell, R., Costa Dias, M., Meghir, C., and Shaw, J. (2011). The Long-term Effects of In-work Benefits in a Life-cycle Model for Policy Evaluation. Centre for Microdata Methods and Practice, Institute for Fiscal Studies 07/11

Blundell, R., Pistaferri, L., and Saporta-Eksten, I. (2012). Consumption Inequality and Family Labor Supply. NBER Working Paper 18445

Blundell, R. and Preston, I. (1998). Consumption Inequality and Income Uncertainty. Quarterly Journal of Economics, 113(2): 603-640

Börsch-Supan, A. and Wilke, C. (2004). The German Public Pension System: How it Was, How it Will Be. NBER Working Paper 10525

Bundesagentur für Arbeit (2013). Arbeitsmarkt 2012 - 60. Jahrgang, Sondernummer 2

Card, D., Lee, D., Pei, Z., and Weber, A. (2012). Nonlinear Policy Rules and the Identification and Estimation of Causal Effects in a Generalized Regression Kink Design. NBER Working Paper 18564

Chan, M.K. (2013). A Dynamic Model of Welfare Reform. Econometrica, 81(3): 9411001

Chetty, R. (2006). A General Formula for the Optimal Level of Social Insurance. Journal of Public Economics, 90(10): 1879-1901 
Chetty, R. (2008). Moral Hazard vs. Liquidity and Optimal Unemployment Insurance. Journal of Political Economy, 116(2): 173-234

Cullen, J. and Gruber, J. (2000). Does Unemployment Insurance Crowd Out Spousal Labor Supply? Journal of Labor Economics, 18(3): 546-572

De Nardi, M., French, E., and Jones, J. (2010). Why do the Elderly Save? The Role of Medical Expenses. Journal of Political Economy, 118(1): 39-75

Eckstein, Z. and Lifshitz, O. (2011). Dynamic Female Labor Supply. Econometrica, 79(6): $1675-1726$

Fernández, R. and Wong, J.C. (2014). Divorce Risk, Wages and Working Wives: A Quantitative Life-Cycle Analysis of Female Labour Force Participation. Economic Journal, 124(576): 319-358

Flemming, J.S. (1978). Aspects of Optimal Unemployment Insurance: Search, Leisure, Savings and Capital Market Imperfections. Journal of Public Economics, 10(3): 403425

French, E. (2005). The Effects of Health, Wealth, and Wages on Labour Supply and Retirement Behaviour. Review of Economic Studies, 72(2): 395-427

Gallant, A.R. and Tauchen, G. (1996). Which Moments to Match? Econometric Theory, 12(4): 657-681

Gourieroux, C., Monfort, A., and Renault, E. (1993). Indirect Inference. Journal of Applied Econometrics, 8(S1): S85-S118

Goux, D., Maurin, E., and Petrongolo, B. (2014). Worktime Regulations and Spousal Labor Supply. American Economic Review, 104(1): 252-276

Gruber, J. (1997). The Consumption Smoothing Benefits of Unemployment Insurance. American Economic Review, 87(1): 192-205

Guvenen, F. (2007). Learning Your Earning: Are Labor Income Shocks Really Very Persistent? American Economic Review, 97(3): 687-712

Haan, P. and Prowse, V. (2014). Longevity, Life-cycle Behavior and Pension Reform. Journal of Econometrics, 178(3): 582-601

Ham, J.C. and Rea, S.A. (1987). Unemployment Insurance and Male Unemployment Duration in Canada. Journal of Labor Economics, 5(3): 325-353

Heathcote, J., Storesletten, K., and Violante, G. (2009). Consumption and Labor Supply with Partial Insurance: An Analytical Framework. NBER Working Paper 15257

Hopenhayn, H. and Nicolini, P. (1997). Optimal Unemployment Insurance. Journal of Political Economy, 105(2): 412-438

Hunt, J. (1995). The Effect of Unemployment Compensation on Unemployment Duration in Germany. Journal of Labor Economics, 13(1): 88-120

Imai, S. and Keane, M.P. (2004). Intertemporal Labor Supply and Human Capital Accumulation. International Economic Review, 45(2): 601-641

Katz, L.F. and Meyer, B.D. (1990). The Impact of the Potential Duration of Unem- 
ployment Benefits on the Duration of Unemployment. Journal of Public Economics, 41(1): 45-72

Keane, M.P. (2014). Life-Cycle Labor Supply with Human Capital: Econometric and Behavioral Implications. Mimeo

Keane, M.P. and Moffitt, R. (1998). A Structural Model of Multiple Welfare Program Participation and Labor Supply. International Economic Review, 39(3): 553-589

Keane, M.P. and Wolpin, K.I. (1997). The Career Decisions of Young Men. Journal of Political Economy, 105(3): 473-522

Lalive, R., van Ours, J., and Zweimüller, J. (2006). How Changes in Financial Incentives Affect the Duration of Unemployment. Review of Economic Studies, 73(4): 1009-1038

Landais, C. (forthcoming). Assessing the Welfare Effects of Unemployment Insurance using the Regression Kink Design. American Economic Journal: Economic Policy

Lentz, R. (2009). Optimal Unemployment Insurance in an Estimated Job Search Model with Savings. Review of Economic Dynamics, 12(1): 37-57

Low, H., Meghir, C., and Pistaferri, L. (2010). Wage Risk and Employment Risk over the Life Cycle. American Economic Review, 100(4): 1432-1467

Low, H. and Pistaferri, L. (2010). Disability Risk, Disability Insurance and Life-cycle Behavior. NBER Working Paper 15962

Lundberg, S. (1985). The Added Worker Effect. Journal of Labor Economics, 3(1): $11-37$

Moffitt, R. and Nicholson, W. (1982). The Effect of Unemployment Insurance on Unemployment: The case of Federal Supplemental Benefits. Review of Economics and Statistics, 64(1): 1-11

Paserman, D. (2008). Job Search and Hyperbolic Discounting: Structural Estimation and Policy Evaluation. Economic Journal, 118(531): 1418-1452

Pavoni, N. (2009). Optimal Unemplyment Insurance with Human Capital Depreciation and Duration Dependence. Internation Economic Review, 50(2): 323-362

Pavoni, N., Setty, O., and Violante, G.L. (2013). Search and Work in Optimal Welfare Programs. NBER Working Paper 18666

Pistaferri, L. (2001). Superior Information, Income Shocks, and the Permanent Income Hypothesis. Review of Economics and Statistics, 83(3): 465-476

Pistaferri, L. (2003). Anticipated and Unanticipated Wage Changes, Wage Risk, and Intertemporal Labor Supply. Journal of Labor Economics, 21(3): 729-754

Saporta-Eksten, I. (2014). Job Loss, Consumption and Unemployment Insurance. Mimeo

Schmieder, J., von Wachter, T., and Bender, S. (2012). The Effects of Extended Unemployment Insurance Over the Business Cycle: Evidence from Regression Discontinuity Estimates Over 20 Years. Quarterly Journal of Economics, 127(2): 701-752 
Shavell, S. and Weiss, L. (1979). The Optimal Payment of Unemployment Insurance Benefits Over Time. Journal of Political Economy, 97(6): 1347-1362

Shimer, R. and Werning, I. (2007). Reservation Wages and Unemployment Insurance. Quarterly Journal of Economics, 122(3): 1145-1185

Shimer, R. and Werning, I. (2008). Liquidity and Insurance for the Unemployed. American Economic Review, 98(5): 1922-1942

Smith, A A, J. (1993). Estimating Nonlinear Time-Series Models Using Simulated Vector Autoregressions. Journal of Applied Econometrics, 8(S1): S63-S84

Spinnewijn, J. (2015). Unemployed but Optimistic: Optimal Insurance Design with Biased Beliefs. Journal of the European Economic Association, 13(1): 130-167

Tatsiramos, K. and van Ours, J.C. (2014). Labor Market Effects of Unemployment Insurance Design. Journal of Economic Surveys, 28(2): 284-311

Todd, P. and Wolpin, K. (2006). Using Experimental Data to Validate a Dynamic Behavioral Model of Child Schooling: Assessing the Impact of a School Subsidy Program in Mexico. American Economic Review, 96(5): 1384-1417

Triebe, D. (2015). The Added Worker Effect Differentiated by Gender and Partnership Status - Evidence from Involuntary Job Loss. SOEPpapers on Multidisciplinary Panel Data Research, 740

van der Klaauw, W. and Wolpin, K.I. (2008). Social Security and the Retirement and Savings Behavior of Low-Income Households. Journal of Econometrics, 145(1-2): $21-42$

Wagner, G., Frick, J., and Schupp, J. (2007). The German Socio-Economic Panel Study (SOEP) - Scope, Evolution and Enhancements. Schmollers Jahrbuch, 127(1): 139-169

Wrohlich, K. (2011). Labor Supply and Child Care Choices in a Rationed Child Care Market. DIW Discussion Paper 1169 